\title{
Structural basis for the inhibition of the Bacillus subtilis c-di-AMP cyclase CdaA by the phosphoglucomutase GlmM
}

Received for publication, May 26, 2021, and in revised form, October 15, 2021 Published, Papers in Press, October 20, 2021, https://doi.org/10.1016/j.jbc.2021.101317

\begin{abstract}
Monisha Pathania , Tommaso Tosi ', Charlotte Millership , Fumiya Hoshiga , Rhodri M. L. Morgan ${ }^{2}$, Paul S. Freemont ${ }^{3,4,5, *}$, and Angelika Gründling ${ }^{1, *}$ (i)

From the ${ }^{1}$ Section of Molecular Microbiology and Medical Research Council Centre for Molecular Bacteriology and Infection, and ${ }^{2}$ Department of Life Sciences, Imperial College London, London, United Kingdom; ${ }^{3}$ London Biofoundry, Imperial College Translation and Innovation Hub, White City Campus, London, United Kingdom; ${ }^{4}$ Section of Structural and Synthetic Biology, Department of Infectious Disease, and ${ }^{5}$ UK Dementia Research Institute Centre for Care Research and Technology, Imperial College London, London, United Kingdom
\end{abstract}

Edited by Wolfgang Peti

Cyclic-di-adenosine monophosphate (c-di-AMP) is an important nucleotide signaling molecule that plays a key role in osmotic regulation in bacteria. $\mathrm{c}$-di-AMP is produced from two molecules of ATP by proteins containing a diadenylate cyclase (DAC) domain. In Bacillus subtilis, the main c-di-AMP cyclase, $\mathrm{CdaA}$, is a membrane-linked cyclase with an $\mathrm{N}$-terminal transmembrane domain followed by the cytoplasmic DAC domain. As both high and low levels of c-di-AMP have a negative impact on bacterial growth, the cellular levels of this signaling nucleotide are tightly regulated. Here we investigated how the activity of the $B$. subtilis $\mathrm{CdaA}$ is regulated by the phosphoglucomutase GlmM, which has been shown to interact with the c-di-AMP cyclase. Using the soluble $B$. subtilis $\mathrm{CdaA}_{\mathrm{CD}}$ catalytic domain and purified full-length GlmM or the

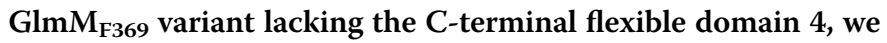
show that the cyclase and phosphoglucomutase form a stable complex in vitro and that GImM is a potent cyclase inhibitor. We determined the crystal structure of the individual B. subtilis $\mathrm{CdaA}_{\mathrm{CD}}$ and GlmM homodimers and of the $\mathrm{CdaA}_{\mathrm{CD}}$ :GlmM $\mathrm{G}_{\mathrm{F} 69}$ complex. In the complex structure, a $\mathrm{CdaA}_{\mathrm{CD}}$ dimer is bound to a $\mathrm{GlmM}_{\mathrm{F} 369}$ dimer in such a manner that GlmM blocks the oligomerization of $\mathrm{CdaA}_{\mathrm{CD}}$ and formation of active head-to-head cyclase oligomers, thus suggesting a mechanism by which GlmM acts as a cyclase inhibitor. As the amino acids at the $\mathrm{CdaA}_{\mathrm{CD}}$ : $\mathrm{GlmM}$ interphase are conserved, we propose that the observed mechanism of inhibition of CdaA by GlmM may also be conserved among Firmicutes.

Nucleotide signaling molecules play important roles in helping bacteria to rapidly adapt to changing environmental conditions $(1,2)$. One such signaling nucleotide, cyclic-diadenosine monophosphate (c-di-AMP), which was discovered a little more than a decade ago (3), plays an important function in the osmotic regulation of bacteria by controlling potassium and osmolyte uptake (4-8). c-di-AMP also plays an

\footnotetext{
* For correspondence: Angelika Gründling, a.grundling@imperial.ac.uk; Paul S. Freemont, p.freemont@imperial.ac.uk.
}

important function in regulating cell size, either directly or indirectly through its function in osmotic regulation, cell-wall integrity, and susceptibility to beta-lactam antibiotics, which target the synthesis of the peptidoglycan cell wall (9-12).

The function of c-di-AMP has been most extensively studied in a range of Firmicutes bacteria including the Grampositive model organism Bacillus subtilis and Gram-positive bacterial pathogens such as Staphylococcus aureus, Listeria monocytogenes, and several Streptococcus species (9, 10, 13-17). From these studies, it has become apparent that the cellular level of c-di-AMP needs to be tightly regulated as both an excess and a lack of c-di-AMP can negatively impact bacterial growth, physiology, and virulence $(17,18)$. To achieve the optimal level, a dynamic equilibrium must exist between the synthesis of c-di-AMP via diadenylate cyclases (DACs) and its degradation into $5^{\prime}$-phosphadenylyl-adenosine (pApA) or two molecules of AMP by phosphodiesterases (18-20). As part of the current study, we investigated how the activity the $B$. subtilis c-di-AMP cyclase CdaA is regulated by GlmM, a phosphoglucomutase enzyme required for the synthesis of an essential peptidoglycan precursor.

c-di-AMP is formed from two molecules of ATP by enzymes containing a DAC domain. These enzymes have been extensively characterized structurally as well as biochemically, but how their activity is regulated is an aspect that remains poorly understood. B. subtilis codes for three DAC enzymes (3, 21-24). CdaA (also referred to as DacA in some bacteria) is a membrane-bound cyclase with three predicted $\mathrm{N}$-terminal transmembrane helices and a cytoplasmic catalytic DAC domain. CdaA (DacA) is the "housekeeping" c-di-AMP cyclase in Firmicutes, as it is conserved and often the sole c-di-AMP cyclase in this phylum $(25,26)$. The two other $B$. subtilis c-diAMP cyclases, DisA and CdaS, are soluble proteins, not as widely distributed among bacteria and have more specialized functions, with DisA involved in controlling DNA-repair processes during sporulation or spore outgrowth and $\mathrm{CdaS}$ also specifically expressed during the sporulation process (22, 23, 27). While there are no publications on the 3D-structures of the B. subtilis c-di-AMP cyclases, structures are available for 


\section{B. subtilis CdaA:GImM complex}

the cytoplasmic enzymatic domains of the $L$. monocytogenes and S. aureus CdaA/DacA homologs $(21,28)$, the DisA homolog from Thermotoga maritima (3), and the CdaS homolog from Bacillus cereus (PDB 2FB5). These studies revealed that DAC domains have a mixed $\alpha ß$-fold, with highly conserved DGA and RHR amino acid motifs required for ligand binding $(3,21,29)$. Formation of c-di-AMP requires a head-to-head conformation of two DAC domains. This was first demonstrated in the crystal structure of DisA, a protein that forms an octamer with four DAC domain dimers in the active head-tohead conformation (3). While the L. monocytogenes and S. aureus CdaA/DacA catalytic domains and the CdaS protein, were also present as dimers and hexamers, respectively, they were in an inactive conformation. These proteins therefore either need to rearrange or more likely form higher oligomers in order to yield active enzymes with DAC domains in the head-to-head dimer conformation $(24,28)$. Recently, another structure of the cytoplasmic catalytic domain of the $L$. monocytogenes CdaA enzyme $(\Delta 100 \mathrm{CdaA})$ has been reported with a c-di-AMP bound between two monomers, which based on the crystal cell packing were arranged in an active dimer of dimer configuration (30). These findings are consistent with the idea that CdaA (DacA) enzymes will need to form higher oligomers to achieve an active enzyme configuration. Hence, factors influencing the ability of c-di-AMP cyclases to rearrange into an active conformation or to form higher oligomers will be able to regulate the activity of these enzymes.

The genetic arrangement and operon structure coding for the "housekeeping" c-di-AMP cyclase CdaA (DacA) is conserved in Firmicutes $(29,31)$. Two genes, coding for the membrane-linked CdaA regulator CdaR (also named YbbR in some bacteria) and cytoplasmically located peptidoglycan precursor synthesis enzyme GlmM, are found downstream and in an operon with $c d a A(29,31)$. Through recent studies in B. subtilis, L. monocytogenes, Lactococcus lactis, and S. aureus, it is has become apparent that these three genes are not only cotranscribed but that the encoded proteins also form a complex and that $\mathrm{CdaR}$ and GlmM can regulate the activity of the c-di-AMP cyclase CdaA (29, 32, 33). While CdaR has been reported to function as both an activator and a repressor of CdaA depending on the growth conditions, GlmM has been shown to be a potent inhibitor of the cyclase $(17,29,31,32$, 34). However, the molecular mechanisms on how the CdaA cyclase activity is regulated by these proteins are not yet known, and this was further investigated as part of this study.

GlmM is a phosphoglucomutase enzyme catalyzing the conversion of glucosamine-6-phosphate to glucosamine-1phosphate, which is subsequently used to produce the essential peptidoglycan precursor UDP-N-acetyl-glucosamine (35). In B. subtilis, L. monocytogenes, and L. lactis, a protein-protein interaction between CdaA and GlmM has been detected using bacterial two-hybrid assays performed in Escherichia coli $(29,31,33)$. In B. subtilis this interaction has been further confirmed by in vivo protein cross-linking and pull-down assays (29) and in L. monocytogenes by the coelution of purified proteins (33). The first evidence that GlmM serves as negative regulator of CdaA/DacA activity came from an L. lactis strain that produces a GlmM variant that is thought to form a stronger interaction with $\mathrm{CdaA}$; this strain produces lower cellular c-di-AMP levels than the bacteria expressing wild-type GlmM (31). Furthermore, the activity of the soluble recombinant $S$. aureus DacA catalytic domain $\left(D \mathrm{~A}_{\mathrm{CD}}\right)$ could be blocked almost completely by the addition of purified GlmM protein in in vitro assays, and the recombinant proteins were shown to form a stable complex that could be purified via sizeexclusion chromatography (28). On the other hand, the activity of GlmM was not affected by the interaction with DacA $_{C D}$ (28). Additional mass spectrometry and small-angle $\mathrm{X}$-ray scattering (SAXS) analyses suggested that the complex is composed of a DacA $_{C D}$ dimer and a GlmM dimer (28). Crystal structures of the individual $S$. aureus $\mathrm{DacA}_{\mathrm{CD}}$ and GlmM dimers revealed that the $S$. aureus DacA $_{\mathrm{CD}}$ protein assumed an "inactive" dimer conformation. GlmM had the typical four-domain fold of phosphoglucomutases with a flexible C-terminal domain 4 and the dimer was "M-shaped," characteristic for this class of enzymes (28). However, a highresolution structure of the complex could not be obtained, and only a model for the complex could be proposed by fitting the individual DacA $\mathrm{A}_{\mathrm{CD}}$ and GlmM dimer structures into the SAXS envelope (28). Based on this, a model was proposed in which GlmM could potentially block the activity of the DacA $A_{C D}$ cyclase by preventing the formation of higher oligomers.

Here, we set out to provide atomic resolution information on the CdaA:GlmM complex to gain insight into the molecular mechanism of how GlmM can control the activity of the c-di-AMP cyclase enzyme. Using the purified B. subtilis $\mathrm{CdaA}$ catalytic domain $\left(\mathrm{CdaA}_{\mathrm{CD}}\right)$ and purified full-length GlmM or the truncated $\mathrm{GlmM}_{\mathrm{F} 369}$ variant lacking the flexible C-terminal domain 4, we show that the two proteins form a stable complex in vitro and that $\mathrm{GlmM}$ and $\mathrm{GlmM}_{\mathrm{F} 369}$ are potent inhibits of the cyclase. Crystal structures of the B. subtilis $\mathrm{CdaA}_{\mathrm{CD}}$ cyclase, the GlmM phosphoglucomutase, and the $\mathrm{CdaA}_{\mathrm{CD}}$ :GlmM $\mathrm{Fl}_{\mathrm{F} 69}$ complex were obtained, revealing dimer conformations of the individual proteins as well as a dimer of dimer conformation in the complex structure. More importantly, from the complex structure the mechanism by which binding of GlmM inhibits the cyclase activity becomes apparent, that is by preventing the oligomerization of CdaA and formation of active head-to-head cyclase oligomers.

\section{Results}

The B. subtilis phosphoglucosamine GImM interacts with and inhibits the activity of the c-di-AMP cyclase $C d a A_{C D}$

Using the purified $S$. aureus DacA $_{\mathrm{CD}}$ catalytic domain and GlmM, it has been shown that the proteins form a stable complex in vitro and that GlmM is a potent inhibitor of the cdi-AMP cyclase without requiring any additional factors (28). To examine if this is also the case for the Bacillus sutbilis proteins, the full-length $B$. subtilis GlmM protein and the truncated $\mathrm{GlmM}_{\mathrm{F} 369}$ variant were expressed and purified along with the soluble catalytic domain of the B. subtilis c-di-AMP cyclase $\mathrm{CdaA}_{\mathrm{CD}}$. The $\mathrm{GlmM}_{\mathrm{F} 369}$ variant lacks the flexible 
C-terminal domain 4 and was constructed to aid subsequent structural investigations. The proteins were expressed as Histagged proteins in E. coli and purified individually via Ni-NTA affinity chromatography followed by size-exclusion chromatography (Fig. 1). To test for a CdaA-GlmM interaction, lysates of strains producing $\mathrm{CdaA}_{\mathrm{CD}}$ and $\mathrm{GlmM}$ (Fig. $1 A$ ) or $\mathrm{CdaA}_{\mathrm{CD}}$ and $\mathrm{GlmM}_{\mathrm{F} 369}$ (Fig. $1 B$ ) were mixed prior to affinity and sizeexclusion chromatography. The elution profiles and analysis of the retention volumes revealed that $\mathrm{CdaA}_{\mathrm{CD}}$ formed a complex with GlmM and with $\mathrm{GlmM}_{\mathrm{F} 369}$ that eluted as a single, highermobility species compared with the individual proteins (Fig. 1). The peak fractions of each complex were further analyzed by SDS-PAGE, confirming the presence of both proteins (Fig. 1, inserts). We also determined the binding affinity between GlmM and $\mathrm{CdaA}_{\mathrm{CD}}$ by microscale thermophoresis (MST). For the MST experiments, increasing concentrations of unlabeled purified GlmM ranging from a final concentration of $0.78 \mu \mathrm{M}$ to $800 \mu \mathrm{M}$ were mixed with fluorescence labeled $\mathrm{CdaA}_{\mathrm{CD}}$ held at a constant final concentration of $25 \mathrm{nM}$ (see Experimental procedures sections for details). Based on the thermophoresis and normalized fluorescence change of $\mathrm{CdaA}_{\mathrm{CD}}$ depending on the GlmM protein concentration, a $K_{d}$ of 14.4 $\mu \mathrm{M} \pm 0.962$ was determined (Fig. 1C) indicating a moderate binding affinity. Next, to determine if the $B$. subtilis GlmM protein impacts the activity of $\mathrm{CdaA}_{\mathrm{CD}}$, in vitro cyclase activity assays were performed, and the conversion of ATP (spiked with a small amount of $\alpha-{ }^{32} P$-labeled ATP) into c-di-AMP assessed. The purified B. subtilis $\mathrm{CdaA}_{\mathrm{CD}}$ protein was enzymatically active in the presence of the divalent metal ion $\mathrm{Mn}^{2+}$ but showed only limited activity in the presence of $\mathrm{Co}^{2+}$ or $\mathrm{Mg}^{2+}$ (Fig. 2A) and after $4 \mathrm{~h}$ incubation approximately $50 \%$ of the ATP substrate was converted to c-di-AMP (Fig. 2B). Addition of GlmM or $\mathrm{GlmM}_{\mathrm{F} 369}$ at a 2:1 M ratio over $\mathrm{CdaA}_{\mathrm{CD}}$ led to a significant reduction in the conversion of ATP to c-di-AMP (Fig. 2C). Taken together, these data show that the purified $B$. subtilis $\mathrm{CdaA}_{\mathrm{CD}}: \mathrm{GlmM}$ and $\mathrm{CdaA}_{\mathrm{CD}}: \mathrm{GlmM}_{\mathrm{F} 369}$ proteins form a stable complex in vitro and that the full-length and truncated GlmM variants inhibit the activity of the c-di-AMP cyclase $\mathrm{CdaA}_{\mathrm{CD}}$.

\section{Crystal structures of the B. subtilis $C d a A_{C D}$ and $G / m M$ proteins}

To gain atomic level details of the $\mathrm{CdaA}_{\mathrm{CD}}$ and $\mathrm{GlmM}$ protein complex, we started off by determining the crystal structures of the individual proteins. The tag-less $B$. subtilis $\mathrm{CdaA}_{\mathrm{CD}}$ protein was crystallized and the structure solved at $2.8 \AA$ (Table 1 and Fig. 3). The protein displayed the expected DAC protein fold, with a central $\beta$-sheet made up of six antiparallel strands flanked by five helices (Fig. $3 A$ ). However, it lacked the seventh $\beta$ strand that was seen in the structures of CdaA homologs of other bacteria $(21,28)$. In B. subtilis $\mathrm{CdaA}_{\mathrm{CD}}$ the residues corresponding to this $\beta$-strand are instead in a loop that adapts a very similar confirmation to the $\beta$ strand observed in other CdaA structures. Superposition of the $B$. subtilis $\mathrm{CdaA}_{\mathrm{CD}}$ structure with the L. monocytogenes $\triangle 100 \mathrm{CdaA}$ (PDB 4RV7; sequence identity of the full-length proteins is 65\%) (21) and S. aureus DacA $_{\mathrm{CD}}$ (PDB 6GYW; sequence identity of the full-length proteins is 53\%) (28) structures, all lacking the $\mathrm{N}$-terminal transmembrane helices, gave r.m.s.ds of 0.79 and 0.75 , respectively, highlighting the overall structural similarities of these enzymes (Fig. $3 B$ ). The B. subtilis $\mathrm{CdaA}_{\mathrm{CD}}$ structure was solved as a dimer in the asymmetric unit with hydrogen-bonding interactions observed at the interaction interface (Fig. 3C). Interactions were observed between the side chains of amino acid residues Asn166, Thr172, and Leu174 (site 1) and residues Leu150, Lys153, and Met155 (site 2) (Fig. 3C). Similar hydrogenbonding interactions were also identified in the $S$. aureus DacA $_{\mathrm{CD}}$ and L. monocytogenes $\triangle 100 \mathrm{CdaA}$ structures with amino acid residues in site 1 being absolutely conserved (28, 30) (Fig. S1). Analysis of the interface with PDBePISA (36) indicated a buried surface of $1400 \AA^{2}$, which is similar to the value of $1460 \AA^{2}$ previously reported for the $S$. aureus $\mathrm{DacA}_{\mathrm{CD}}$ protein, indicative of a stable dimer formation. In this dimer
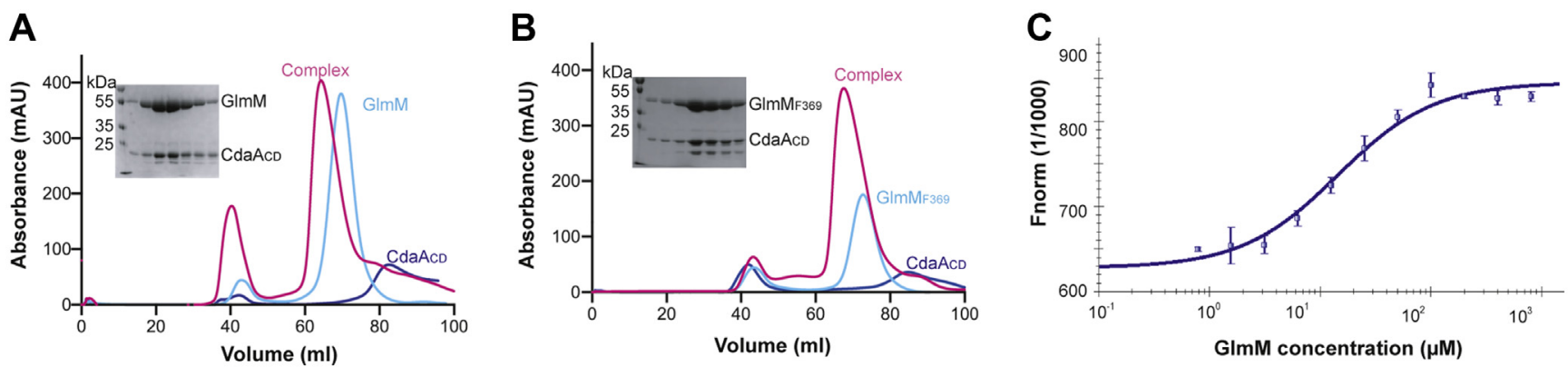

Figure 1. The B. subtilis $\mathrm{GImM}$ and $\mathrm{CdaA}_{\mathrm{CD}}$ proteins form a complex in vitro. $A, \mathrm{FPLC}$ chromatograms and SDS-PAGE gel analysis of the $B$. subtilis $C$ daA $\mathrm{A}_{\mathrm{CD}}$ and $\mathrm{GlmM}$ complex. The $B$. subtilis proteins $\mathrm{CdaA}_{C D}, \mathrm{GlmM}$, and the $\mathrm{CdaA}_{C D} / \mathrm{GlmM}$ complex were purified by Ni-affinity chromatography and size-exclusion chromatography. The FPLC elution profiles, recorded at a wavelength of $280 \mathrm{~nm}$, are shown for CdaA $\mathrm{CD}_{\mathrm{C}}(\mathrm{b} / \mathrm{lue}), \mathrm{GlmM}$ (cyan) and the CdaA $\mathrm{CD} / \mathrm{GlmM}$ complex (pink). Proteins from the peak fractions of the $\mathrm{CdaA}_{C D}-\mathrm{GlmM}$ complex were separated on a $12 \%$ SDS PAGE gel and proteins visualized by Coomassie staining (shown in the insert). $B$, FPLC chromatograms and SDS-PAGE gel analysis of the $B$. subtilis $\mathrm{CdaA}_{\mathrm{CD}}$ and $\mathrm{GlmM}_{\mathrm{F} 369}$ complex. Same as in ( $A$ ) but using the $\mathrm{C}$ terminally truncated $\mathrm{GlmM}_{\mathrm{F} 369}$ variant in place of the full-length $\mathrm{GlmM}$ protein. The experiments were performed in triplicates and representative chromatograms and gel images are shown. $C$, MST experiment to determine the binding affinity between $C$ daA $A_{C D}$ and GImM. Increasing concentrations of GlmM were mixed with fluorescently labeled $\mathrm{CdaA}_{\mathrm{CD}}$ resulted in a gradual change in thermophoresis and fluorescence readings. The normalized fluorescence values multiplied by a factor of 1000 Fnorm (1/1000) were plotted using the NT Analysis Software (NanoTemper Technologies GmbH) to yield the binding curve. The data points are the average values and standard deviations from five independent MST runs. The $K_{d}$ was determined from these data using the NT Analysis Software (NanoTemper Technologies GmbH). 

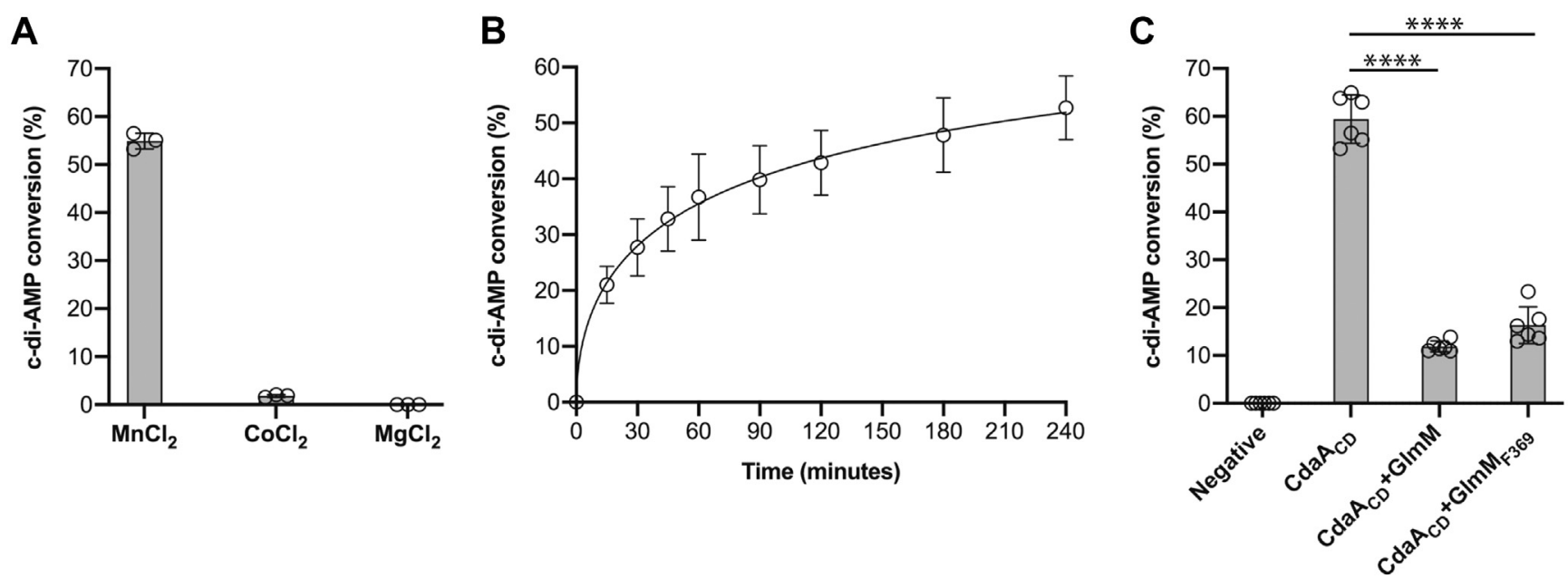

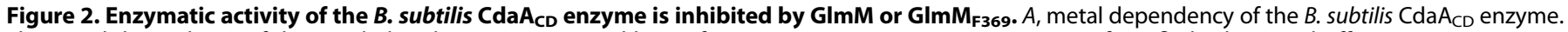
The metal dependency of the $B$. subtilis $C \mathrm{CdaA}_{C D}$ was assessed by performing enzyme reactions using $5 \mu M$ of purified $C$ daA $A_{C D}$ in buffer containing $10 \mathrm{mM}$ $\mathrm{Mn}^{+2}, \mathrm{Mg}^{+2}$, or Co ${ }^{+2}$ ions. After $4 \mathrm{~h}$ of incubation, the reactions were stopped, separated by TLC, and the percentage conversion of radiolabeled ATP to c-diAMP determined. The average values and standard deviations (SDs) from three experiments were plotted. $B$, CdaA $A_{C D}$ activity time-course experiment. Enzyme reactions were set up with the $B$. subtilis $C \mathrm{CdaA}_{\mathrm{CD}}$ enzyme in buffer containing $10 \mathrm{mM} \mathrm{Mn} \mathrm{N}^{+2}$, aliquots removed, and reactions stopped at the indicated time points and separated by TLC. The percentage conversion of radiolabeled ATP to c-di-AMP was determined and the average values and SDs from three independent experiments plotted. $C$, enzyme activity of the $B$. subtilis $C$ daA $A_{C D}$ enzyme in the presence of $B$. subtilis GlmM. The enzyme activity of $\mathrm{CdaA}_{C D}$ was measured in the absence or presence of $\mathrm{GlmM}$ or $\mathrm{GlmM}_{\mathrm{F} 369}$ at a molar ratio of 2:1 $\mathrm{GlmM}$ or $\mathrm{GlmM} \mathrm{F}_{\mathrm{F} 69}$ to $\mathrm{CdaA} \mathrm{A}_{\mathrm{CD}}$. After $4 \mathrm{~h}$ of incubation, the reactions were stopped, separated by TLC, and the percentage conversion of radiolabeled ATP to c-di-AMP was determined. The average values and SDs from six independent experiments were plotted. One-way ANOVA tests followed by Dunnett's multiple comparison were performed to identify statistically significant differences in cyclase activity in the absence or presence of $\mathrm{GlmM}$ or $\mathrm{GlmM}_{\mathrm{F} 369}{ }^{* * *}$ indicates $p<0.0001$.

confirmation, the active sites face opposite directions and hence cannot be engaged in a catalytically active head-to-head conformation (Fig. $3 A$ ). Taken together, these data indicate that the conformationally inactive dimerization interface is conserved among different CdaA homologs in Gram-positive bacteria and that the enzyme needs to form higher oligomers for catalysis.

The His-tagged B. subtilis GlmM protein was crystallized and the structure solved by molecular replacement using the Bacillus anthracis GlmM structure (PDB 3PDK; (37)) as the search model (Table 1 and Fig. 3D). The B. subtilis GlmM protein displayed a four-domain architecture typical for phosphoglucosamine mutase proteins $(28,37)$ (Fig. $3 D$ ). Domains 1 to 3 are comprised of $\alpha-\beta$ mixed cores linked via a flexible loop to domain 4, which displays a three-stranded $\beta$ sheet fold surrounded by two $\alpha$-helices (Fig. 3D). While one GlmM molecule was present in the asymmetric unit, the typical "M-shaped" GlmM dimer arrangement was observed in the crystal cell packing (Fig. S2). Interactions were formed between domains 1 , leading to the formation of a large groove

Table 1

Crystallographic data and refinement statistics

\begin{tabular}{|c|c|c|c|c|c|}
\hline Structure parameters & $\mathrm{CdaA}_{\mathrm{CD}}$ & $\begin{array}{c}\mathrm{GlmM} \\
\left(\mathrm{PO}_{4} \text { bound }\right)\end{array}$ & $\begin{array}{c}\text { GlmM } \\
\text { (metal bound) }\end{array}$ & $\begin{array}{c}\mathrm{CdaA}_{\mathrm{CD}} \text { and } \\
\mathrm{GlmM}_{\mathrm{F} 369} \text { complex 1 }\end{array}$ & $\begin{array}{c}\mathrm{CdaA}_{\mathrm{CD}} \text { and } \\
\mathrm{GlmM}_{\mathrm{F} 369} \text { complex } 2\end{array}$ \\
\hline \multicolumn{6}{|l|}{ Data collection } \\
\hline Space group & $\mathrm{P} 4_{3} 2_{1} 2$ & $\mathrm{P} 3{ }_{2} 21$ & $\mathrm{P} 3{ }_{2} 21$ & P $122_{1} 1$ & P $122_{1} 1$ \\
\hline \multicolumn{6}{|l|}{ Cell dimensions } \\
\hline$a, b, c(\AA)$ & $62.88,62.88,187.32$ & $134.87,134.87,69.18$ & $134.41,134.41,69.01$ & $62.20,227.56,151.60$ & $62.80,228.53,153.19$ \\
\hline$\alpha, \beta, \gamma\left({ }^{\circ}\right)$ & $90.00,90.00,90.00$ & $90.00,90.00,120.00$ & $90.00,90.00,120.00$ & $90.00,99.66,90.00$ & $90.00,99.86,90.00$ \\
\hline Resolution $(\AA ̊)$ & $93.66(2.8)^{\mathrm{a}}$ & $48.290(3.0)^{\mathrm{a}}$ & $48.15(2.9)^{\mathrm{a}}$ & $61.32(3.65)^{\mathrm{a}}$ & $76.18(4.2)^{\mathrm{a}}$ \\
\hline Unique reflections & $9974(1396)^{\mathrm{a}}$ & $14,081(2497)^{\mathrm{a}}$ & $15,955(2503)^{\mathrm{a}}$ & $45,925(4441)^{\mathrm{a}}$ & $31,005(4490)^{\mathrm{a}}$ \\
\hline Rpim & $0.05(0.52)^{\mathrm{a}}$ & $0.13(2.58)^{\mathrm{a}}$ & $0.09(1.46)^{\mathrm{a}}$ & $0.019(0.15)^{\mathrm{a}}$ & $0.06(0.22)^{\mathrm{a}}$ \\
\hline $\mathrm{CC}_{(1 / 2)}$ & $0.99(0.97)^{\mathrm{a}}$ & $0.54(0.54)^{\mathrm{a}}$ & $0.99(0.39)^{\mathrm{a}}$ & $0.99(0.53)^{\mathrm{a}}$ & $0.78(0.39)^{\mathrm{a}}$ \\
\hline$I / \sigma(I)$ & $18.2(5.9)^{a}$ & $6.9(2.4)^{a}$ & $12.6(4.4)^{\mathrm{a}}$ & $5.5(1.2)^{\mathrm{a}}$ & $2.1(0.9)^{\mathrm{a}}$ \\
\hline Completeness (\%) & $100.0(100.0)^{\mathrm{a}}$ & $99.9(99.5)^{\mathrm{a}}$ & $98.8(97.3)^{\mathrm{a}}$ & $99.6(99.2)^{\mathrm{a}}$ & $99.9(99.9)^{\mathrm{a}}$ \\
\hline Redundancy & $23.2(24.1)^{\mathrm{a}}$ & $19.6(17.3)^{\mathrm{a}}$ & $20.2(17.5)^{\mathrm{a}}$ & $6.9(7.1)$ & $3.8(3.8)^{a}$ \\
\hline \multicolumn{6}{|l|}{ Refinement } \\
\hline Resolution $(\AA)$ & 2.8 & 3.0 & 2.9 & 3.6 & 4.2 \\
\hline$R_{\text {work }} / R_{\text {free }}(\%)^{\mathrm{b}}$ & $0.2545 / 0.2966$ & $0.1996 / 0.2589$ & $0.1868 / 0.2348$ & $0.2418 / 0.2615$ & $0.2473 / 0.2976$ \\
\hline \multicolumn{6}{|l|}{ Rms deviations } \\
\hline Bond lengths $(\AA)$ & 0.008 & 0.016 & 0.0015 & 0.003 & 0.003 \\
\hline Bond angles $\left({ }^{\circ}\right)$ & 1.192 & 1.533 & 1.396 & 0.658 & 0.703 \\
\hline \multicolumn{6}{|l|}{ Ramachandran plot (\%) } \\
\hline Most favored/outliers & $89.82 / 2.11$ & $95.71 / 0.68$ & $87.36 / 1.81$ & $92.49 / 1.44$ & $92.94 / 0.88$ \\
\hline PDB code & 6HUW & 7OJR & $7 \mathrm{OML}$ & 7OLH & 7OJS \\
\hline
\end{tabular}

${ }^{a}$ Refers to the highest resolution shell.

${ }^{b} \mathrm{R}_{\text {free }}$ was computed same as $\mathrm{R}_{\text {work, }}$ using a test set ( $\left.\sim 5 \%\right)$ of randomly selected reflections that were omitted from the refinement. 
A

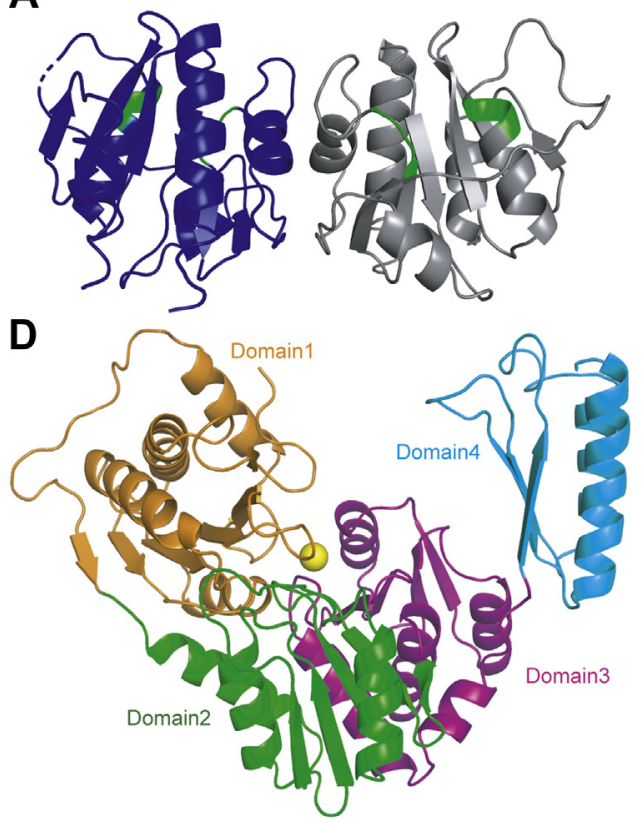

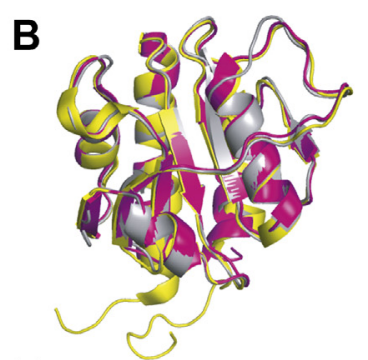

E

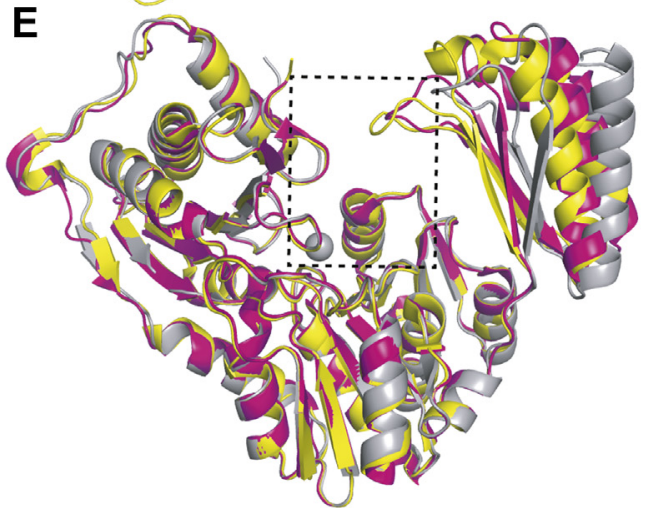

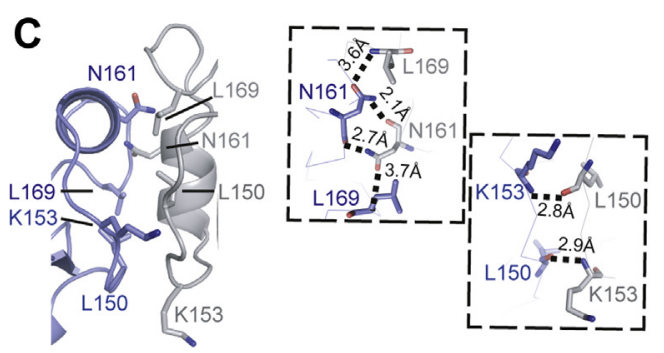

$\mathbf{F}$

Figure 3. Crystal structures of the $B$. subtilis $\mathbf{C d a A}_{C D}$ and $\mathrm{GlmM}$ enzymes. $A, B$. subtilis $\mathrm{CdaA}_{C D}$ structure in cartoon representation. The $C d a A_{C D}$ protein crystallized as dimer and individual $C \mathrm{CdaA}_{C D}$ monomers are shown in blue and gray, with active site DGA and RHR motifs highlighted in green. $B$, superimposition of the B. subtilis, L. monocytogenes and S. aureus $\mathrm{CdaA}_{\mathrm{CD}}$ (DacA $\mathrm{ADD}_{\mathrm{CD}}$ ) structures. Monomers of the B. subtilis CdaA $\mathrm{A}_{\mathrm{CD}}$ (gray), L. monocytogenes CdaA $\mathrm{CD}_{\mathrm{CD}}$ (yellow; PDB ID 4RV7), and S. aureus DacA $A_{C D}$ (pink; PDB ID 6GYW) protein structures were superimposed using COOT (48). $C, C$ CdaA $A_{C D}$ dimer interface and zoomed in view showing residues Leu150, Lys153, Asn161, and Leu169, which form hydrogen-bonds, in stick representation. D, B. subtilis GlmM structure in cartoon representation. The GlmM protein crystalized as a dimer (Fig. S2) with one monomer in the asymmetric unit. The GlmM monomer displayed the typical 4 domain architecture, and the individual domains are represented in different colors. A metal ion was bound to the protein and is shown as yellow sphere. $E$, superposition of the B. subtilis, S. aureus and B. anthracis GlmM structures. B. subtilis GlmM (gray), B. anthracis GlmM (yellow; PDB 3PDK), and S. aureus GImM (pink; PDB 6GYX) monomer structures were superimposed using COOT (48). F, zoomed in view of the superimposed B. subtilis (gray; metalion bound structure), S. aureus (pink) and B. anthracis (yellow) GlmM structures showing the distances between the indicated Arg residue within the phosphate binding site and the active site Ser residue. Images were generated using PyMOL (The PyMOL Molecular Graphics System, Version 2.0 Schrödinger, LLC).

at the top of the dimer molecule, mostly formed by domain 2 and the active site of each monomer subunit facing the opposite direction. Two different structures were solved for the B. subtilis GlmM protein at 2.9 and $3.0 \AA$ resolutions with a superposition r.m.s.d. score of 0.29 (Table 1 and Fig. S2). One of the crystal structures was obtained with a divalent cation bound to the catalytic serine residue, which during catalysis is thought to be converted to a phosphoserine residue and the metal ion playing an important role during catalysis (Fig. S2). The exact type of metal ion could not be deduced due to the limitation of the structural resolution. However, we speculate that it is a magnesium ion, as magnesium was present in the crystallization conditions, and this metal ion is usually also bound in fully active enzymes. Furthermore, when a magnesium ion was modeled into the structure and analyzed using the program CheckMyMetal (38), a better fit was observed as compared with zinc or calcium ions, which could also fill the density. In the second structure, a phosphate molecule $\left(\mathrm{PO}_{4}\right)$ was bound to $\operatorname{Arg} 419$, located within a loop region in domain 4 (Fig. S2B) at a similar location as observed in the B. anthracis GlmM structure (37). The superimposition of the B. subtilis GlmM structure with the $S$. aureus (6GYZ; (28)) and B. anthracis (3PDK; (37)) GlmM structures gave small r.m.s.d. values of 1.0261 and 1.0668 , respectively (Fig. $3 E$ ), indicating high similarity. However, the interresidue distance between
Arg419 in the phosphate-binding site in domain 4 and the catalytic Ser100 in domain 1 was $20.22 \AA$ in the phosphate bound B. subtilis GlmM structure compared with $18.4 \AA$ in the S. aureus GlmM (PDB 6GYZ) or $15.18 \AA$ in the B. anthracis GlmM (PDB 3PDK) structures (Fig. 3F). This highlights the flexibility of domain 4 in GlmM enzymes and also reveals that the B. subtilis GlmM protein was captured in most open state of the enzyme reported so far in a crystal structure.

\section{Structure of the B. subtilis $C d a A_{C D}: G / m M_{F 369}$ complex}

To understand how GlmM interacts and inhibits CdaA, we next aimed to obtain the structure of the complex. Any crystals obtained for the B. subtilis $\mathrm{CdaA}_{\mathrm{CD}}$ :GlmM complex diffracted poorly. On the other hand, diffracting crystals were obtained for the $\mathrm{CdaA}_{\mathrm{CD}}: \mathrm{GlmM}_{\mathrm{F} 369}$ complex, in which the $\mathrm{GlmM}$ protein lacks the flexible C-terminal domain 4. The crystals were obtained under two different conditions (see Experimental procedures section), and the structure of the $\mathrm{CdaA}_{\mathrm{CD}}$ :GlmM $\mathrm{G}_{\mathrm{F} 369}$ complex could be solved at $3.6 \AA$ (Complex 1) and at $4.2 \AA$ (Complex 2) by molecular replacement using the $B$. subtilis $\mathrm{CdaA}_{\mathrm{CD}}$ and $\mathrm{GlmM}$ (dimer) structures as search models (Table 1, Figs. 4 and S3). While obtained under two different conditions, complex 1 and complex 2 were nearly identical and overlapped with an r.m.s.d. of $0.22 \AA$ (Fig. S4.A). 


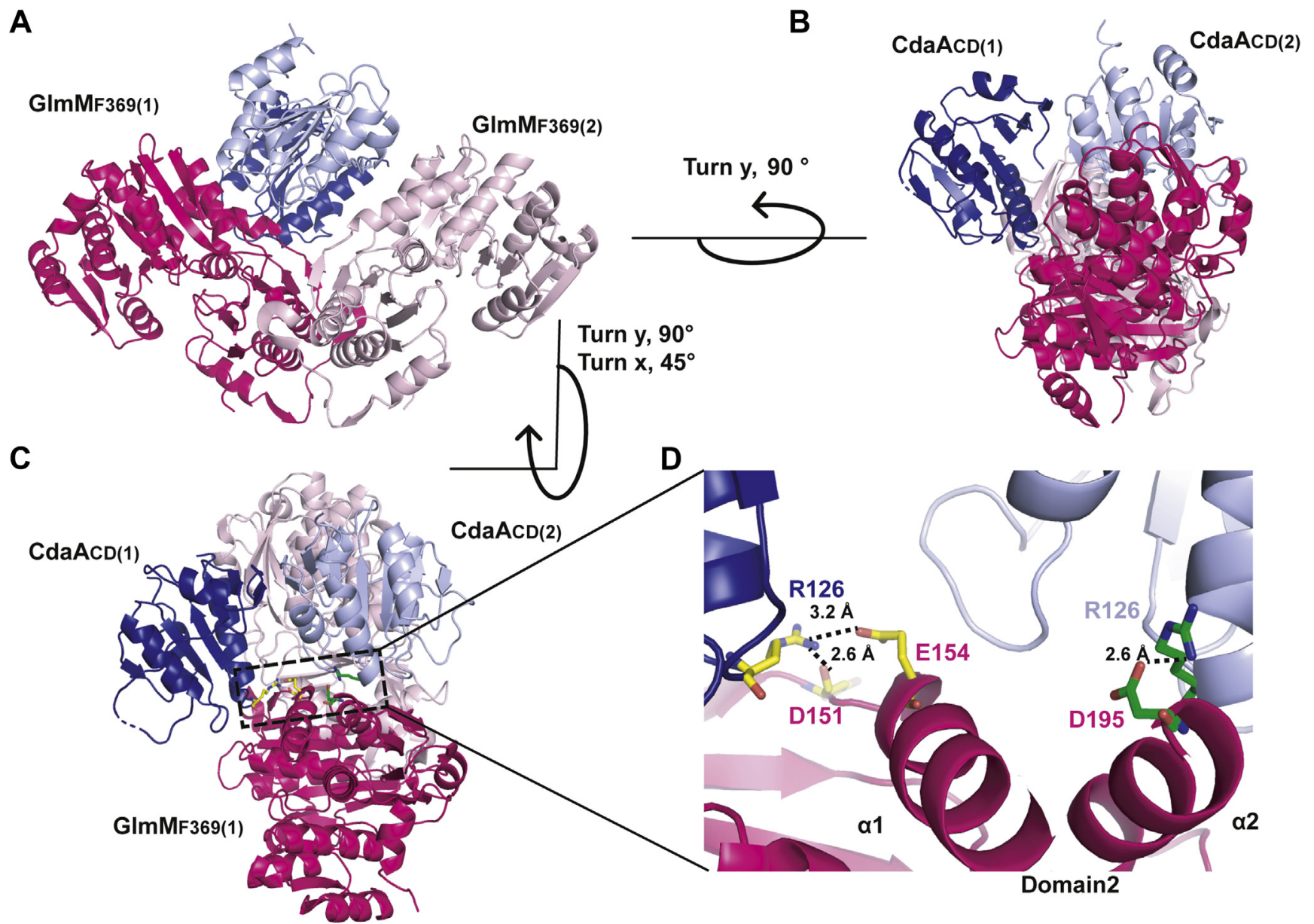

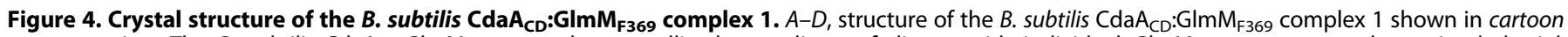
representation. The $B$. subtilis $\mathrm{CdaA}_{\mathrm{CD}}: \mathrm{GlmM}_{\mathrm{F} 369}$ complex crystallized as a dimer of dimers with individual GlmM $\mathrm{F}_{\mathrm{F} 369}$ monomers shown in dark pink $\left[\mathrm{GlmM}_{\mathrm{F} 369}(1)\right]$ and light pink [GlmM $\left.\mathrm{F}_{\mathrm{F} 69}(2)\right]$ and individual $\mathrm{CdaA}_{\mathrm{CD}}$ monomers shown in dark blue $\left[\mathrm{CdaA}_{\mathrm{CD}}(1)\right]$ and light blue [CdaA $\left.\mathrm{AD}_{\mathrm{CD}}(2)\right]$, respectively. The complex is show in $A$, in front view, $B$, in side view (rotated $90^{\circ}$ along the $y$-axis) and $C$, in top-side view rotated at the angle as indicated with respect to $(A)$. $D$, a zoom in view of the $C_{d a A} A_{C D} / G l m M_{F 369}$ interface is shown. Residue $A r g 126$ from $C_{d a A} A_{C D}(1)$ forms $H$-bond and ionic interactions with Asp 151 and Glu154 of $\mathrm{GlmM}_{\mathrm{F} 369}(1)$ (residues shown in yellow), and residue $\operatorname{Arg} 126$ from CdaA $\mathrm{CD}_{\mathrm{CD}}(2)$ forms ionic interactions with Asp195 in $\mathrm{GlmM}_{\mathrm{F} 369}(1)$ (residues shown in green). The images were prepared in PyMOL (The PyMOL Molecular Graphics System, Version 2.0 Schrödinger, LLC).

Furthermore, in both complex structures, three complex molecules were obtained in the asymmetric unit and each complex was composed of a $\mathrm{GlmM}_{\mathrm{F} 369}$ dimer and a $\mathrm{CdaA} \mathrm{A}_{\mathrm{CD}}$ dimer in the inactive dimer configuration (Figs. 4 and S3). The three complexes obtained in the asymmetric unit were almost identical to each other, as indicated by the superposition r.m.s.d. of 0.15 to $0.20 \AA$ for complex 1 (Fig. S4B) and of 0.15 to $0.16 \AA$ for complex 2 (Fig. S4C). Since the obtained complex structures were basically identical, all further descriptions are based on the higher resolution complex 1 structure. In the complex, a $\mathrm{CdaA}_{\mathrm{CD}}$ dimer was positioned in the large groove at the top of the $\mathrm{GlmM}_{\mathrm{F} 369}$ dimer and formed interactions with domain 2 of GlmM (Fig. 4, $A-C$ ). The complex was asymmetric, with one of the $\mathrm{CdaA}_{\mathrm{CD}}$ monomers, $\mathrm{CdaA}_{\mathrm{CD}}(2)$ (shown in light blue in Fig. 4) placed in the center of the $\mathrm{GlmM}_{\mathrm{F} 369}$ groove and the other monomer, $\mathrm{CdaA}_{\mathrm{CD}}(1)$ (shown in dark blue in Fig. 4) projecting toward the solvent. Similarly, most of the interactions of the $\mathrm{GlmM}_{\mathrm{F} 369}$ dimer with the $\mathrm{CdaA}_{\mathrm{CD}}$ dimer were made by $\mathrm{GlmM}_{\mathrm{F} 369}$ (1) (shown in dark pink in Fig. 4). PDBePISA analysis revealed an average buried surface area of $996 \AA^{2}$ in the interface between $\operatorname{GlmM}_{\mathrm{F} 369}(1)$ and the $\mathrm{CdaA}_{\mathrm{CD}}$ dimer, which was stabilized by four hydrogen bond and four ionic bond interactions between $\operatorname{GlmM}_{\mathrm{F} 369}(1)$ and $\mathrm{CdaA}_{\mathrm{CD}}(1)$ and five hydrogen bond and three ionic bond interactions with $\mathrm{CdaA}_{\mathrm{CD}}(2)$ (Table S1 and Fig. S5). On the other hand, only an average $220.3 \AA^{2}$ surface area is occluded in $\mathrm{GlmM}_{\mathrm{F} 369}$ (2) (shown in light pink in Fig. 4). Based on the PDBePISA analysis, $\operatorname{GlmM}_{\mathrm{F} 369}(2)$ only formed two hydrogen bond interactions with the $\mathrm{CdaA}_{\mathrm{CD}}(2)$ monomer but no interaction with $\mathrm{CdaA}_{\mathrm{CD}}(1)$ (Table S1 and Fig. S5). A more detailed analysis of the interface showed that several interactions are made between two $\alpha$-helices from domain 2 of $\operatorname{GlmM}_{\mathrm{F} 369}(1), \alpha 1$ and $\alpha 2$, with the $\mathrm{CdaA}_{\mathrm{CD}}(1)$ and $\mathrm{CdaA}_{\mathrm{CD}}(2)$ monomers, respectively (Fig. $4, C$ and $D$ ). The main interactions in the complex were formed between three residues, $\mathrm{D} 151, \mathrm{E} 154$, and D194 of domain 2 in $\operatorname{GlmM}_{\mathrm{F} 369}(1)$ and residue $\mathrm{R} 126$ in each of the $\mathrm{CdaA}_{\mathrm{CD}}$ monomers. More specifically, ionic bonds were formed between residue D195 in $\mathrm{GlmM}_{\mathrm{F} 369}(1)$ and residue $\mathrm{R} 126$ in $\mathrm{CdaA}_{\mathrm{CD}}$ (2). In addition, salt bridges were formed between residues D151 and E154 in 
$\operatorname{GlmM}_{\mathrm{F} 369}(1)$ and residue $\mathrm{R} 126$ but this time from $\mathrm{CdaA}_{\mathrm{CD}}(1)$ (Fig. 4, $C$ and $D$, Table $\mathrm{S} 2$ and Fig. S5). The data suggest that residue $\mathrm{R} 126$ in $\mathrm{CdaA}_{\mathrm{CD}}$ is potentially one of the most critical residues for complex formation, as it contributes to a number of ionic as well as hydrogen-bond interactions and even though the complex is asymmetric, it contributes to interactions in both $\mathrm{CdaA}_{\mathrm{CD}}$ monomers.

\section{$\mathrm{CdaA}_{C D}$ cannot form active oligomers in complex with GImM}

To gain insight of how GlmM inhibits the activity of the c-di-AMP cyclase, we inspected the location of the active sites of $\mathrm{CdaA}_{\mathrm{CD}}$ in the complex. The active site of DAC-domain enzymes is characterized by DGA and RHR motifs, corresponding to residues $\mathrm{D}_{171} \mathrm{GA}$ and $\mathrm{R}_{203} \mathrm{HR}$ in B. subtilis CdaA (Fig. 5; areas highlighted in yellow and green in the $\mathrm{CdaA}_{\mathrm{CD}}$ monomers). The active site in $\mathrm{CdaA}_{\mathrm{CD}}(2)$ was completely occluded upon interaction with the $\mathrm{GlmM}_{\mathrm{F} 369}$ dimer (Fig. 5, dark blue $\mathrm{CdaA}_{\mathrm{CD}}$ monomer with active site region highlighted in yellow) but the active site in $\mathrm{CdaA}_{\mathrm{CD}}(1)$ appeared at least partially exposed (Fig. 5; light blue $\mathrm{CdaA}_{\mathrm{CD}}$ monomer with active site region highlighted in green). For $\mathrm{CdaA}_{\mathrm{CD}}$ to produce c-di-AMP active head-to-head dimers need to be formed (3). The crystal structure of the L. monocytogenes $\triangle 100 C$ daA cyclase was recently determined with a c-di-AMP molecule bound in the catalytic site and an active head-tohead dimer conformation seen in the crystal packing (30). Using the L. monocytogenes $\Delta 100 \mathrm{CdaA}$ structure (PDB $6 \mathrm{HVL}$ ) as model, an active $B$. subtilis $\mathrm{CdaA}_{\mathrm{CD}}$ dimer was modeled and superimposed on $\mathrm{CdaA}_{\mathrm{CD}}(1)$ in the complex structure (Fig. 5). Although the active site of the $\mathrm{CdaA}_{\mathrm{CD}}(1)$ was exposed and accessible in the complex with $\mathrm{GlmM}_{\mathrm{F} 369}$, in an active dimer conformation, parts of the second $\mathrm{CdaA}_{\mathrm{CD}}$ molecule would collide and overlap with $\mathrm{GlmM}_{\mathrm{F} 369}$, highlighting that also $\mathrm{CdaA}_{\mathrm{CD}}(1)$ cannot form active head-to-head oligomers in the complex (Fig. 5). Taken together, these data indicate that in the complex, the interaction of $\mathrm{GlmM}$ with $\mathrm{CdaA}_{\mathrm{CD}}$ will prevent the formation of functional DAC enzyme oligomers, which is essential for the formation of c-di-AMP. The crystal structure of the $\mathrm{CdaA}_{\mathrm{CD}}: \mathrm{GlmM}_{\mathrm{F} 369}$ complex therefore
A

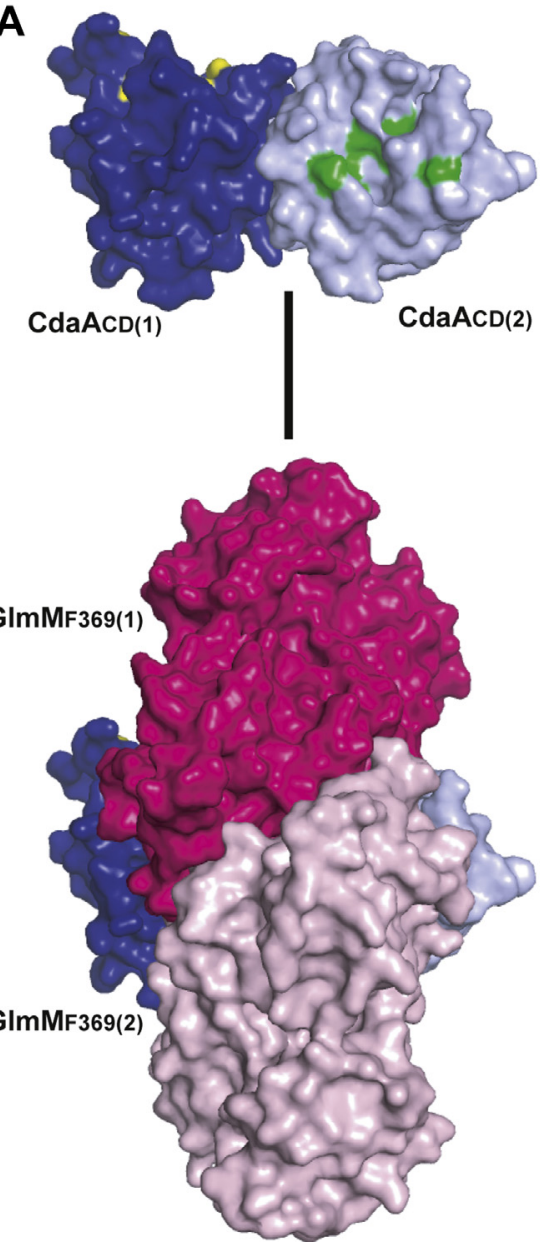

B

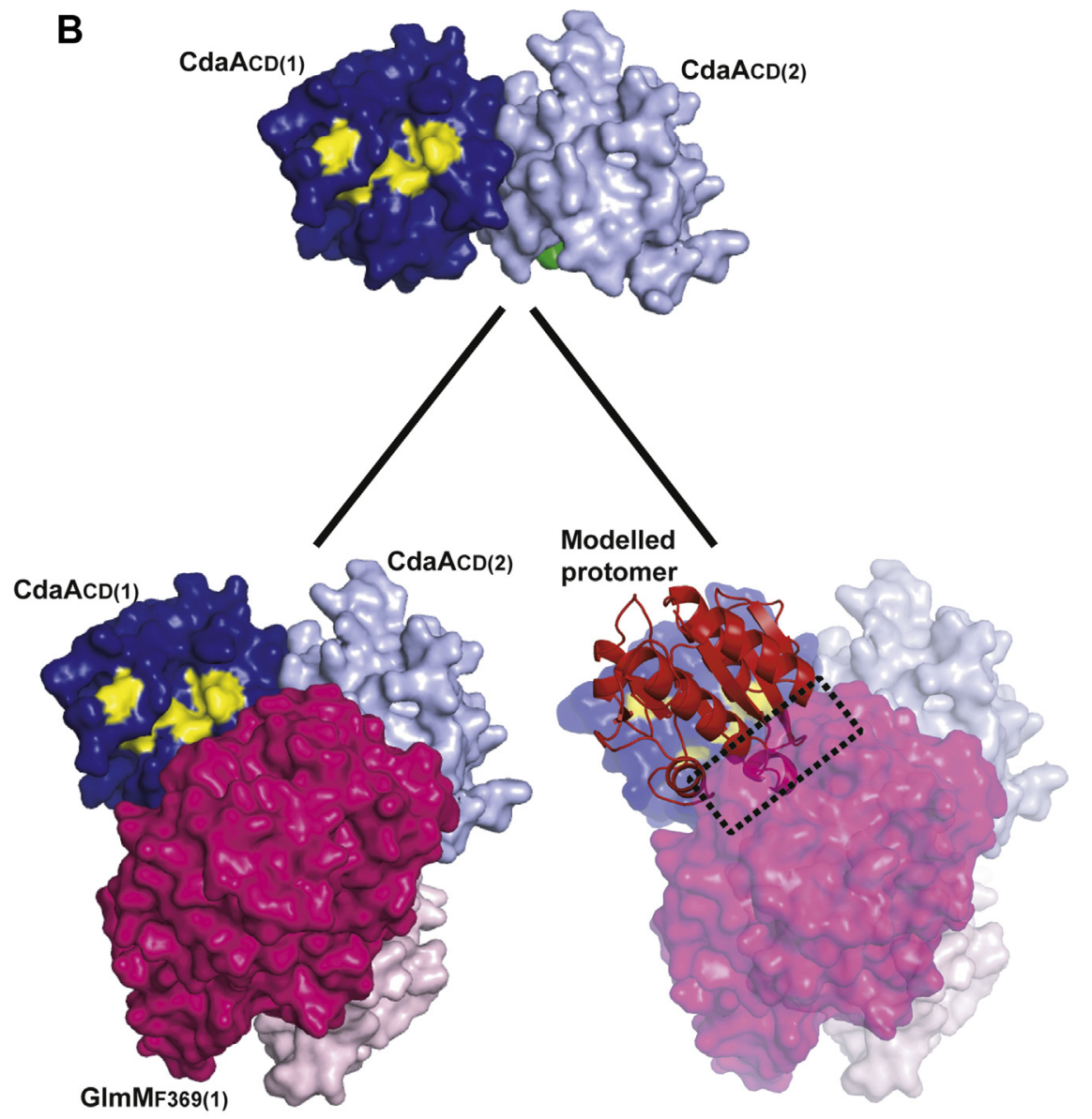

Figure 5. Formation of an active $\mathbf{C d a A}_{\mathrm{CD}}$ dimer is blocked in the complex. $A$ and $B$, structure of the $B$. subtilis $C$ daA $\mathrm{A}_{\mathrm{CD}}$ dimer from complex 1 (top panels) and the complete $\mathrm{CdaA}_{\mathrm{CD}}: \mathrm{GlmM}_{\mathrm{F} 369}$ complex 1 (bottom panels) shown as space filling models. The active site DGA and RHR motifs in CdaA $\mathrm{CD}_{\mathrm{CD}}(1)$ (dark blue protomer) are shown in yellow and in $\mathrm{CdaA}_{\mathrm{CD}}$ (2) (light blue protomer) in green. $A$, bottom panel, complex model showing that the active site (green residues) in $\mathrm{CdaA}_{\mathrm{CD}}$ (2) (light blue protomer) are completely occluded in the complex and $B$, the active site (yellow residues) of $C$ daA $A_{C D}(1)($ dark blue protomer) remains partially exposed. However, the modeling of another $\mathrm{CdaA}_{C D}$ protomer (in red) that forms an active dimer with $\mathrm{CdaA}_{C D}(1)(\mathrm{dark}$ blue protomer) results in protein-protein clashes with the $\mathrm{GlmM}_{\mathrm{F} 369}(1)$ monomer in the complex. The active $\mathrm{CdaA}_{\mathrm{CD}}$ dimer was modeled based on the $L$. monocytogenes $\Delta 100 \mathrm{CdaA}$ (PDB 6HVL) structure (30). 


\section{B. subtilis CdaA:GImM complex}

provides insight on an atomic level on the catalytic inhibition of the DAC $\mathrm{CdaA}_{\mathrm{CD}}$ by the phosphoglucosamine enzyme GlmM.

\section{Small-angle $X$-ray scattering analysis of $B$. subtilis $\mathrm{CdaA}_{C D}: G \operatorname{lmM}$ complex}

To determine whether the full-length $B$. subtilis GlmM protein interacts with $\mathrm{CdaA}_{\mathrm{CD}}$ in a similar manner as observed for $\mathrm{GlmM}_{\mathrm{F} 369}$, a structural characterization of the $\mathrm{CdaA}_{\mathrm{CD}}$ :GlmM complex was performed via small-angle X-ray scattering (SAXS). To this end, the individual purified B. subtilis $\mathrm{CdaA}_{\mathrm{CD}}$ and GlmM proteins as well as the purified $\mathrm{CdaA}_{\mathrm{CD}}$ :GlmM complex and as control the $\mathrm{CdaA}_{\mathrm{CD}}: \mathrm{GlmM}_{\mathrm{F} 369}$ complex were passed over an analytical size-exclusion column, followed by continuous automated SAXS data collection throughout the run (Figs. 6 and S6, Table S2). For $\mathrm{CdaA}_{\mathrm{CD}}$ and $\mathrm{GlmM}$, the reconstructed maps were consistent with the proteins forming dimers and the maps were a good fit for the B. subtilis $\mathrm{CdaA}_{\mathrm{CD}}$ dimer (Fig. 6A) and GlmM dimer (Fig. 6B) structures, respectively. The reconstructed map for the $\mathrm{CdaA}_{\mathrm{CD}}$ :GlmM complex $\left(\mathrm{V}_{\mathrm{c}}\right.$ : 890.1, $\mathrm{R}_{\mathrm{g}}: 44.65 \AA$, and $\mathrm{d}_{\max }: 161 \AA$ ) was bigger in volume and dimensions as compared with the individual maps calculated for $\operatorname{GlmM}\left(\mathrm{V}_{\mathrm{c}}: 625.8 ; \mathrm{R}_{\mathrm{g}}: 37.29 \AA, \mathrm{d}_{\text {max }}: 122 \AA\right)$ and $\mathrm{CdaA}_{\mathrm{CD}}\left(\mathrm{V}_{\mathrm{c}}\right.$ : 373.2, $\mathrm{R}_{\mathrm{g}}: 26.94 \AA, \mathrm{d}_{\text {max }}: 88 \AA$ ), which is consistent with the formation of a complex. From the Guinier plot analysis, the molecular weight of the B. subtilis $\mathrm{CdaA}_{\mathrm{CD}}$ :GlmM complex was calculated to be $130 \mathrm{kDa}$, which is consistent with the theoretical molecular weight of $144.46 \mathrm{kDa}$ for a complex made of two $\mathrm{CdaA}_{\mathrm{CD}}$ and two GlmM molecules. To fit a $\mathrm{CdaA}_{\mathrm{CD}}$ :GlmM dimer complex into the reconstructed map, a model of the complex with full-length GlmM was first constructed by superimposing the crystal structure of full-length $\mathrm{GlmM}$ onto the $\mathrm{CdaA}_{\mathrm{CD}}: \mathrm{GlmM}_{\mathrm{F} 369}$ complex structure. The resulting complex model was subsequently fitted in the

\section{A}
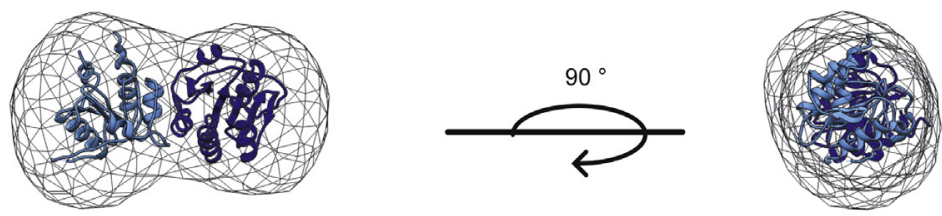

B
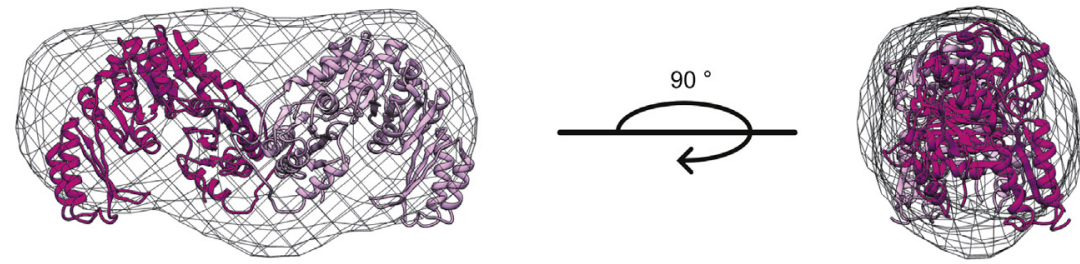

C
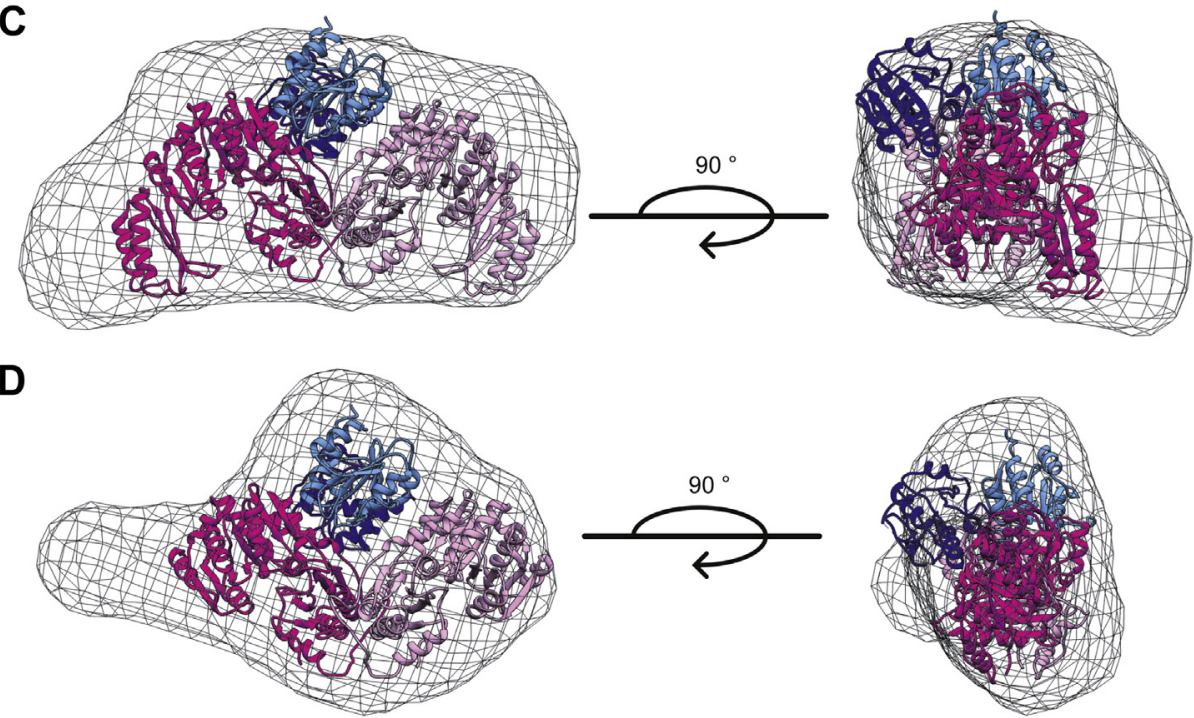

Figure 6. Small-angle X-ray scattering (SAXS) data of the $B$. subtilis $\mathrm{CdaA}_{\mathrm{CD}}$, GImM proteins and the CdaA $A_{\mathrm{CD}}: \mathrm{GlmM}_{\mathrm{m}}$ and $\mathrm{CdaA}_{\mathrm{CD}}: \mathrm{GlmM}_{\mathrm{F} 369} \mathrm{Com}_{\mathrm{C}}$ plexes. $A-D$, SAXS envelopes with fitted protein structures. For the SAXS experiment, $50 \mu \mathrm{l}$ of $\mathrm{CdaA}_{\mathrm{CD}}(5 \mathrm{mg} / \mathrm{ml}), \mathrm{GlmM}(24 \mathrm{mg} / \mathrm{ml})$ and the complex $\mathrm{CdaA}_{C D}: \mathrm{GlmM}(24 \mathrm{mg} / \mathrm{ml})$ and the $\mathrm{CdaA}_{\mathrm{CD}}: \mathrm{GlmM}_{\mathrm{F} 369}$ complex $(10 \mathrm{mg} / \mathrm{ml})$ were injected onto a high pressure Shodex column coupled to the B21 SmallAngle X-Ray beamline at the Diamond Light Source. The data analysis and envelope reconstruction were performed using ScÅtter (51). The program Chimera (53) was used to visualize the reconstructed envelopes as maps into which the protein structures were fitted. $A$, SAXS envelope of the $B$. subtilis $\mathrm{CdaA}_{C D}$ protein with a $\mathrm{CdaA}_{C D}$ dimer protein structure fitted into the envelope. $B$, SAXS envelope of the $B$. subtilis GlmM protein with the GlmM protein dimer structure fitted into the envelope. $C$, SAXS envelope of the $B$. subtilis $C$ daA $A_{C D}: G l m M$ complex with a CdaA $A_{C D}: G l m M$ dimer model structure fitted into the envelope. $D$, SAXS envelope of the $B$. subtilis $C_{C d a A}$ :GlmM $M_{F 369}$ complex with the structure of $C_{C d a A}: G l m M F 369$ dimer complex fitted into the envelope. 
reconstituted SAXS envelope of the complex. A good fit of the $\mathrm{CdaA}_{\mathrm{CD}}$ :GlmM dimer model complex into the reconstructed envelope was observed; however, an elongated density on one side remained unoccupied (Fig. $6 \mathrm{C}$ ). It is plausible that the flexible C-terminal domain 4 of the GlmM protein is responsible for this extra density. As control, an SAXS experiment was also performed using the $\mathrm{CdaA}_{\mathrm{CD}}$ :GlmM $\mathrm{Gl}_{\mathrm{F} 69}$ complex sample for which the $\mathrm{X}$-ray structure was obtained. The dimensions of the $\mathrm{CdaA}_{\mathrm{CD}}: \mathrm{GlmM}_{\mathrm{F} 369}$ complex were $\mathrm{V}_{\mathrm{c}}: 656.8$, $\mathrm{R}_{\mathrm{g}}: 37.51 \AA$, and $\mathrm{d}_{\text {max }}: 117.5 \AA$ and the molecular weight was calculated to be $97.5 \mathrm{kDa}$, which is consistent with the theoretical molecular weight of $120 \mathrm{kDa}$ for a complex made of two $\mathrm{CdaA}_{\mathrm{CD}}$ and two GlmM $\mathrm{F}_{699}$ molecules. Similarly, a good fit of the $\mathrm{CdaA}_{\mathrm{CD}}: \mathrm{GlmM}_{\mathrm{F} 369}$ dimer complex structure was obtained when fitted into the reconstructed SAXS envelope data (Fig. 6D). These data suggest that the full-length GImM protein likely forms a dimer-of-dimer complex with the c-di-AMP cyclase $\mathrm{CdaA}_{\mathrm{CD}}$ and might assume a similar arrangement as observed for the $\mathrm{CdaA}_{\mathrm{CD}}: \mathrm{GlmM}_{\mathrm{F} 369}$ complex.

\section{Arginine 126 in B. subtilis $C d a A_{C D}$ is essential for complex formation}

The complex structure highlighted key interactions between residues D194 and residues D151/E154 in GlmM with residue $\mathrm{R} 126$ in each of the $\mathrm{CdaA}_{\mathrm{CD}}$ monomers (Fig. 5D). To confirm our structural findings, a site-directed mutagenesis analysis was performed. To this end, D195A, D151A/E154A, and D151A/E154A/D191A alanine substitution GlmM variants were created. Furthermore, residue R126 in $\mathrm{CdaA}_{\mathrm{CD}}$, which in both monomers makes contacts with GlmM, was mutated to an alanine. The different alanine substitution variants were expressed and purified from $E$. coli and complex formation assessed by size-exclusion chromatography. While our initial experiments using the GlmM single, double, and triple alanine substitution variants appeared not to or only marginally affect complex formation with $\mathrm{CdaA}_{\mathrm{CD}}$ (Fig. S7), no complexspecific peak was observed when the interaction between the $\mathrm{CdaA}_{\mathrm{CD}}-\mathrm{R} 126 \mathrm{~A}$ variant and GlmM was assessed. Instead, two peaks were observed for the $\mathrm{CdaA}_{\mathrm{CD}}-\mathrm{R} 126 \mathrm{~A}: \mathrm{GlmM}$ sample, one corresponding to the retention volume of GlmM and the another to $\mathrm{CdaA}_{\mathrm{CD}}-\mathrm{R} 126 \mathrm{~A}$ (Fig. $7 A$ ). Analysis of the elution fractions from the $\mathrm{CdaA}_{\mathrm{CD}}-\mathrm{R} 126 \mathrm{~A} / \mathrm{GlmM}$ sample by SDSPAGE and Coomassie staining showed that only a very small fraction of the $\mathrm{CdaA}_{\mathrm{CD}}-\mathrm{R} 126 \mathrm{~A}$ protein coeluted with $\mathrm{GlmM}$ (Fig. 7A). These data highlight that, consistent with the structural data, residue $\mathrm{R} 126$ in $\mathrm{CdaA}_{\mathrm{CD}}$ plays a key role for the complex formation with GlmM. Based on these data, it can be predicted that the cyclase activity of the $\mathrm{CdaA}_{\mathrm{CD}}-\mathrm{R} 126 \mathrm{~A}$ variant should no longer be inhibited by GImM. To test this experimentally, in vitro cyclase enzyme activity assays were performed. The $\mathrm{CdaA}_{\mathrm{CD}}-\mathrm{R} 126 \mathrm{~A}$ variant was active, although the activity was reduced as compared with wild-type $C \mathrm{CdaA}_{\mathrm{CD}}$ (Fig. $7 B$ ). Importantly and in contrast to wild-type $\mathrm{CdaA}_{\mathrm{CD}}$, the enzyme activity of this variant was no longer inhibited by the addition of GlmM (Fig. $7 B$ ). These data show that residue Arg126 in B. subtilis $\mathrm{CdaA}_{\mathrm{CD}}$ plays a critical role for complex formation and that GlmM can only inhibit the activity of the c-di-AMP cyclase after the formation of a stable complex.

\section{Discussion}

In this study, we show that the B. subtilis GlmM and $\mathrm{CdaA}_{\mathrm{CD}}$ cyclase domain form a stable dimer-of-dimer complex. GlmM acts through this protein-protein interaction as a potent inhibitor of the c-di-AMP cyclase without requiring any additional factors. Based on the atomic-resolution complex structure data, we suggest that GlmM inhibits the activity of
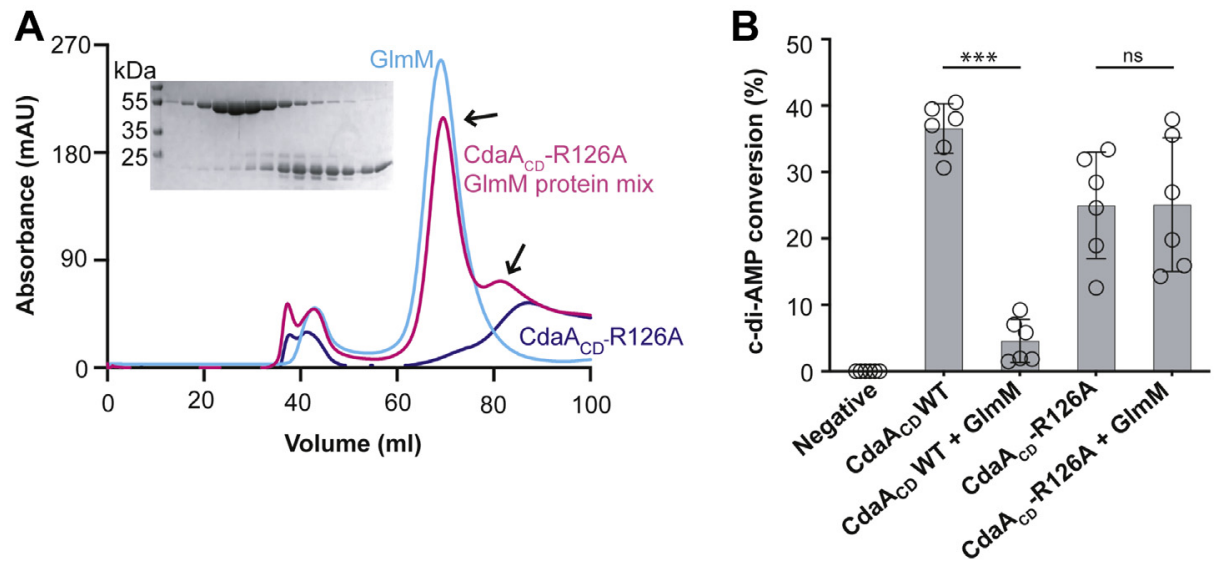

Figure 7. Residue Arg126 in B. subtilis CdaA $A_{C D}-R 126 A$ is important for complex formation with GImM. $A$, FPLC chromatograms and SDS-PAGE gel analysis of the $B$. subtilis $C \mathrm{CdaA}_{C D}-\mathrm{R} 126 \mathrm{~A}$, GlmM, and a mix of both proteins. The $B$. subtilis $C \mathrm{CdaA}_{C D}-\mathrm{R} 126 \mathrm{~A}, \mathrm{GlmM}$, and the $C$ daA $\mathrm{AD}_{C D}-\mathrm{R} 126 \mathrm{~A} / \mathrm{GlmM}$ protein mixture were purified by Ni-affinity chromatography and size-exclusion chromatography. The FPLC elution profiles, recorded at a wavelength of 280 nm, are shown for $\mathrm{CdaA}_{C D}-\mathrm{R} 126 \mathrm{~A}$ (blue), GImM (cyan) and the $\mathrm{CdaA}_{C D}-\mathrm{R} 126 \mathrm{~A} / \mathrm{G} / \mathrm{mM}$ mixture (pink). Proteins from the peak fractions of the $\mathrm{CdaA} \mathrm{AD}_{\mathrm{CD}}-\mathrm{R} 126 \mathrm{~A} / \mathrm{G} / \mathrm{mM}$ sample were separated on a $12 \%$ SDS PAGE gel and proteins visualized by Coomassie staining (shown in the insert). The experiments were performed in triplicates and representative chromatograms and gel images are shown. $B$, enzymatic activity of wild-type $C d a A_{C D}$ and the $C$ daA $A_{C D}-R 126 A$ protein variant in the absence or presence of $\mathrm{GlmM}$. Enzyme activity assays were performed with $5 \mu \mathrm{M}$ purified $\mathrm{CdaA} \mathrm{A}_{\mathrm{CD}}$ or $\mathrm{CdaA}_{\mathrm{CD}}-\mathrm{R} 126$ in the absence or presence of $10 \mu \mathrm{M}$ GlmM protein. After $4 \mathrm{~h}$ of incubation, the reactions were stopped, separated by TLC, and the percentage conversion of radiolabeled ATP to c-di-AMP determined. The average values and SDs from six experiments were plotted. T-tests were performed to determine statistically significant differences in enzyme activity of $\mathrm{CdaA}_{C D}$ or $\mathrm{CdaA}_{C D}-\mathrm{R} 126 \mathrm{~A}$ in the absence or presence of $\mathrm{GlmM}$. ns indicates not statistically significant; ${ }^{* * *}$ indicates $p<0.001$. 


\section{B. subtilis CdaA:GImM complex}

$\mathrm{CdaA}_{\mathrm{CD}}$ by preventing the formation of active head-to-head cyclase oligomers.

For CdaA to produce c-di-AMP, two monomers need to be arranged in an active head-to-head conformation. As part of this study, we determined the structure of the B. subtilis $\mathrm{CdaA}_{\mathrm{CD}}$ protein and show that it has the typical DAC domain fold. While the protein was also found as a dimer in the structure, the dimer was in an inactive conformation, with the two active sites facing in opposite directions. The interface creating the inactive dimer conformation is conserved among CdaA proteins. The L. monocytogenes and S. aureus homologs, for which structures are available, were found in the same inactive dimer conformation even though the proteins crystallized under different conditions and were found in different space groups $(21,28,30)$. This makes it less likely that a crystallographic symmetry artifact is responsible for the observed inactive dimer configuration. In addition to the inactive dimer configuration within an asymmetric unit, an active dimer conformation was observed in the L. monocytogenes $\Delta 100 \mathrm{CdaA}$ protein by inspecting adjacent symmetry units (30). However, no such active dimer head-tohead conformations were identified for the $B$. subtilis $\mathrm{CdaA}_{\mathrm{CD}}$ protein across different symmetry units in the current structure. While not further investigated as part of this study, previous work on the $S$. aureus homolog indicated that the inactive dimer conformation is very stable, and in order for the protein to produce an active enzyme, the protein needs to form higher-level oligomers (28). Given the similarity in the interaction interface, this is likely also the case for the $B$. subtilis $\mathrm{CdaA}_{\mathrm{CD}}$ enzyme, and we would suggest that the B. subtilis $\mathrm{CdaA}_{\mathrm{CD}}$ dimer observed in the structure is unlikely to rearrange into an active dimer conformation.

We also solved the structure of the B. subtilis GlmM enzyme. The protein assumed the typical 4-domain architecture previously reported for GlmM enzymes $(28,37)$ and the "M shape" in the dimer conformation, which in the case of the Bacillus sutbtilis GlmM protein was formed across two adjacent crystallographic units. The B. subtilis GlmM structure further highlighted the flexibility of the most C-terminal domain 4, which was found in the most open conformation seen in any GlmM protein structure up to date. The conformational flexibility of domain 4 is probably also a main factor why we were unsuccessful in determining the structure of a complex between $\mathrm{CdaA}_{\mathrm{CD}}$ and full-length GlmM. However, GlmM domain 4 is not required for the interaction with and inhibition of $\mathrm{CdaA}_{\mathrm{CD}}$, since a $B$. subtilis $\mathrm{GlmM}$ variant lacking domain 4 formed a complex and inhibited the activity of B. subtilis $\mathrm{CdaA}_{\mathrm{CD}}$. Furthermore, by using the B. subtilis $\mathrm{GlmM}_{\mathrm{F} 369}$ variant lacking the flexible domain 4, we were able to obtain the structure of the $\mathrm{CdaA}_{\mathrm{CD}}$ : $\mathrm{GlmM}_{\mathrm{F} 369}$ complex, revealing for the first time structural details at the atomic level for this complex, thereby identifying the amino acids important for the interaction between the two proteins. Several electrostatic interactions were detected between $\mathrm{CdaA}_{\mathrm{CD}}: \mathrm{GlmM}_{\mathrm{F} 369}$ between the negatively charged residues D151, E154, and D195 in domain 2 of B. subtilis GlmM $\mathrm{F}_{\mathrm{F} 69}$ with the positively charged residue $\mathrm{R} 126$ in $\mathrm{CdaA}_{\mathrm{CD}}$. We could further show that replacing residue $\mathrm{R} 126$ in $\mathrm{CdaA}_{\mathrm{CD}}$ with an alanine abolished complex formation and the activity of the $\mathrm{CdaA}_{\mathrm{CD}}-\mathrm{R} 126$ variant was no longer inhibited by GlmM. A direct protein-protein interaction between CdaA and GlmM has now been reported for these proteins in several Firmicutes bacteria, and hence the amino acids required for the interaction might be conserved. Indeed, a ConSurf (39) analysis using $250 \mathrm{CdaA}$ protein sequences showed that the residue corresponding to R126 in B. subtilis CdaA is conserved between the different homologs (Fig. S8). Likewise, all the three negatively charged residues, D151, E154, and D195 in GlmM, which mediate the primary electrostatic interactions with R126 of $\mathrm{CdaA}_{\mathrm{CD}}$, are highly conserved (Fig. S8). In previous work, we have shown that the $S$. aureus $\mathrm{DacA}_{\mathrm{CD}}$ (the $\mathrm{CdaA}_{\mathrm{CD}}$ homolog) does not interact with GlmM proteins from E. coli and Pseudomonas aeruginosa, two Gram-negative bacteria (28). While negatively charged amino acids corresponding to residues E154 and D195 in B. subtilis GlmM are also found in the GlmM protein from the Gram-negative bacteria (D153 and E194 in E. coli and D152 and E193 in P. aeruginosa), the amino acids at the equivalent position of D151 in B. subtilis GlmM are an arginine residue ( $\mathrm{R} 150$ in $E$. coli and $\mathrm{R} 149$ in $P$. aeruginosa), which may hinder the complex formation between CdaA (DacA), and GlmM proteins of Gram-negative bacteria (28).

In a previous work, we proposed a model whereby GlmM inhibits the activity of CdaA cyclase activity by preventing the formation of active head-to-head oligomers (28). In the absence of an actual atomic resolution structure of the complex, this model was based on SAXS envelope data and fitting individual protein structures. The model predicted that the likely interaction site between CdaA and GlmM proteins is domain 2 of GlmM (28). The structure of B. subtilis $\mathrm{CdaA}_{\mathrm{CD}}$ :GlmM $\mathrm{F}_{\mathrm{F} 39}$ complex we present here now provides experimental evidence for such a model and shows that GlmM indeed inhibits the activity of the CdaA cyclase in vitro by preventing the formation of active head-to-head oligomers. The $K_{d}$ between $\mathrm{CdaA}_{\mathrm{CD}}$ and GlmM was in the $\mu \mathrm{M}$ range, which will likely allow complex formation and dissociation in response to changes in protein levels and/or changes in cellular or environmental conditions. GlmM is an essential metabolic enzyme required for the synthesis of the peptidoglycan precursor glucosamine-1-P and thought to be predominantly located within the cytoplasm of the cell (33). However, based on the work presented in this study and previous findings, it is assumed that under certain conditions, a fraction of GlmM will localize to the bacterial membrane and interact with and inhibit the activity of the membrane-linked c-di-AMP cyclase CdaA (DacA) $(28,32,33)$. As a result of this interaction, cellular c-di-AMP levels would decrease and consequently potassium and osmolyte uptake will increase. Recent work on L. monocytogenes suggests that GlmM regulates $\mathrm{CdaA}$ during hyperosmotic stress conditions, as during these conditions, overexpression of GlmM has been shown to result in a decrease in cellular c-di-AMP levels (33). The resulting activation of potassium and osmolyte transporters due to a drop in cellular c-di-AMP levels will help cells to 
counteract the water loss under osmotic stress conditions and aid in bacterial survival. However, what exact cellular changes caused by the osmotic upshift lead to a relocalization of GlmM to the membrane to form a complex with CdaA is currently not known and will require further investigation.

The level of c-di-AMP is regulated by a fine balance between the activities of the cyclase, which synthesizes c-di-AMP, and the phosphodiesterases, which break it down. Interestingly, these two classes of enzyme appear to be regulated very differently; whereas the activity of several phosphodiesterases has been shown to be regulated by small molecules, cyclase activity appears to be regulated through protein-protein interaction. For example, the stringent response alarmone (p) ppGpp has been shown to inhibit the activity both GdpP and PgpH enzymes $(11,20)$. Furthermore, binding of heme to the Per-ARNT-Sim (40) signaling domain in GdpP (which is separate from its DHH/DHHA1 enzymatic domain that is responsible for the degradation of c-di-AMP) was shown in in vitro enzyme assays to result in reduced phosphodiesterase activity (40). Interestingly, the ferrous form of heme bound to GdpP could form a pentacoordinate complex with nitric oxide (NO), resulting in increased c-di-AMP phosphodiesterase activity. Based on these data it has been suggested that GdpP is a heme or NO sensor, resulting in decreased or increased activity respectively (41). The function consequence and impact of (p)ppGpp, heme, or NO binding to the phosphodiesterases on bacterial physiology have not yet been fully investigated. However, from these data it is clear that the activity of the c-diAMP phosphodiesterases can be regulated by small-molecule ligands.

On the other hand, several proteins have been found to interact with and regulate the activity of c-di-AMP cyclases. The B. subtilis DisA protein is involved in monitoring the genomic stability ensuring that damaged DNA is repaired before cells progress with the sporulation process or exit from spores $(27,42)$. DisA is encoded in a multigene operon and the gene immediately upstream of disA codes for RadA (also referred to as SMS). B. subtilis RadA possesses $5^{\prime}$ to $3^{\prime}$ DNA helicase activity, contributes to DNA repair and DNA transformation processes in B. subtilis, and has been shown to interact and negatively impact the activity of DisA (27). However, the mechanistic basis of how RadA binding to DisA inhibits the cyclase is currently not known. There is now ample evidence that the activity of the "house-keeping" membrane-linked c-di-AMP cyclase CdaA is impacted by two interacting proteins, the membrane-linked regulator protein CdaR and the cytoplasmic phosphoglucomutase enzyme $\operatorname{GlmM}(29,33)$. We have provided experimental evidence for the mechanistic basis by which GlmM inhibits the activity of CdaA, that is, by preventing the formation of active higherlevel oligomers. How CdaR regulates the cyclase activity of CdaA remains unclear. Recent work on the homologous proteins in L. monocytogenes indicated that the interaction of CdaA with CdaR takes place via the N-terminal transmembrane region of $\mathrm{CdaA}$ and $\mathrm{GlmM}$ has been shown to interact directly with the cytoplasmic cyclase domain of CdaA in $S$. aureus $(28,33)$. Here, we show that this is also the case for the B. subtilis GlmM protein, which can bind without the requirement of any additional factor to the catalytic $\mathrm{CdaA}_{\mathrm{CD}}$ domain. In future works, it will be interesting to determine the structure of the full-length CdaA enzyme, which might provide further insight into how the enzyme forms higher oligomers for activity as well as how it interacts with CdaR. Furthermore, it will be interesting to further investigate the interaction between GlmM and CdaR with CdaA within bacterial cells to determine if this interaction is dynamic and which stimuli will promote or prevent complex formation to fine-tune the synthesis of c-di-AMP. Identifying how interacting proteins regulate the activity of these cyclases will provide important insight of how bacterial cells maintain proper levels of c-diAMP under different growth conditions and in different environments.

\section{Experimental procedures \\ Bacterial strains and plasmid construction}

All bacterial strains and primers used in this work are listed in Tables S3 and S4, respectively. pET28b-derived plasmids were constructed for the overproduction of the $\mathrm{C}$-terminal catalytic domain of the B. subtilis CdaA enzyme starting from amino acid Phe97 and referred to as $\mathrm{CdaA}_{\mathrm{CD}}$, GlmM, and the $\mathrm{GlmM}_{\mathrm{F} 369}$ variant comprising residues Met1 to Phe369 but lacking the C-terminal domain 4. To this end, the corresponding DNA fragments were amplified by PCR using B. subtilis strain 168 chromosomal DNA as template and primer pairs ANG2760/ANG2761 ( $\left.c d a A_{C D}\right)$, ANG2762/ ANG2763 $(g \operatorname{lm} M)$, and ANG2762/ANG2764 $\left(g \operatorname{lm} M_{F 369}\right)$. The PCR products were purified, digested with NheI/BamHI $\left(c d a A_{C D}\right)$ or NcoI/XhoI ( $g \operatorname{lm} M$ and $\left.g \operatorname{lm} M_{F 369}\right)$ and ligated with pET28b, which had been cut with the same enzyme. $\mathrm{CdaA}_{\mathrm{CD}}$ was cloned in frame with an N-terminal thrombin cleavable 6-histidine tag, while $\mathrm{GlmM}$ and $\mathrm{GlmM}_{\mathrm{F} 369}$ were cloned in frame with a C-terminal 6-histidine tag and a thrombin cleavage site was introduced in front of the His-tag as part of the primer sequence. The resulting plasmids pET28b-his$c d a A_{C D}, \mathrm{pET} 28 \mathrm{~b}-g \operatorname{lm} M$-his, and pET28b-glmM $M_{F 369}$-his were initially recovered in E. coli XL1-Blue, yielding the strains ANG4583, ANG4584, and ANG4585 and subsequently transformed for protein expression into strain E. coli BL21(DE3), yielding strains ANG4597, ANG4598, and ANG4599, respectively. Plasmids pET28b-his-cdaA $A_{C D}-R 126$, pET28b-glmM-D194A-his, pET28b-glmM-D151A/E154A-his were constructed for the expression of $\mathrm{CdaA}_{\mathrm{CD}}$ and $\mathrm{GlmM}$ alanine substitution variants. The plasmids were constructed by QuikChange mutagenesis using pET28b-his-cdaA $A_{C D}$ and primer pair ANG3373/ANG3374 or plasmid pET28b-glmMhis and primer pairs ANG3381/ANG3382 and ANG3383/ 3384 , respectively. The plasmids were initially recovered in E. coli XL1-Blue, yielding strains ANG5933, ANG5937, ANG5938 and subsequently introduced for protein expression into E. coli strain BL21(DE3) yielding strains ANG5940, ANG5944, ANG5945. In addition, plasmid pET28b-glmMD151A/E154A/D194A-his for expression of a GlmM variant with a triple Asp151 (D151), Glu154 (E154), and Asp195 


\section{B. subtilis CdaA:GImM complex}

(D195) alanine substitution variant was constructed by QuikChange mutagenesis using plasmid pET28b-glmM-D194A-his as template and primer pair ANG3383/3384 to introduce the D151A and E154A mutations. Plasmid pET28b-glmM-D151A/ E154A/D194A-his was recovered in E. coli strain XL1-Blue, yielding strain ANG5939 and subsequently introduced for protein expression into strain BL21(DE3) yielding strain ANG4946. The sequences of all plasmid inserts were verified by fluorescent automated sequencing at Eurofins.

\section{Protein expression, purification, and quantification}

Proteins $\mathrm{CdaA}_{\mathrm{CD}}$, GlmM, and $\mathrm{GlmM}_{\mathrm{F} 369}$ were expressed and purified from 11 cultures as previously described (28). Briefly, when bacterial cultures reached an $\mathrm{OD}_{600}$ of approximately 0.6, protein expression was induced with $1 \mathrm{mM}$ IPTG (final concentration) for $3 \mathrm{~h}$ at $37^{\circ} \mathrm{C}$. Cells were harvested by centrifugation, suspended in $20 \mathrm{ml}$ of $50 \mathrm{mM}$ Tris $\mathrm{pH} 7.5$, $500 \mathrm{mM} \mathrm{NaCl}$ buffered, and lysed using a French Press system. Lysates were clarified by centrifugation and the supernatant loaded onto a gravity flow column with $3 \mathrm{ml}$ of Ni-NTA resin. Immobilized proteins were washed with $20 \mathrm{ml}$ of $50 \mathrm{mM}$ Tris $\mathrm{pH} 7.5,500 \mathrm{mM} \mathrm{NaCl}, 50 \mathrm{mM}$ imidazole buffer, and eluted in $5 \times 1 \mathrm{ml}$ fractions using $50 \mathrm{mM}$ Tris $\mathrm{pH} 7.5,200 \mathrm{mM} \mathrm{NaCl}$, $500 \mathrm{mM}$ imidazole buffer. Fractions containing the proteins were pooled and loaded onto a preparative Superdex 200 HiLoad 16/60 column equilibrated with one column volume of $30 \mathrm{mM}$ Tris $\mathrm{pH} 7.5,150 \mathrm{mM} \mathrm{NaCl}$ buffer. When appropriate, the purified proteins were concentrated using $10 \mathrm{ml} 10 \mathrm{kDa}$ cutoff Amicon concentrators for downstream applications. For the purification of the $\mathrm{CdaA}_{\mathrm{CD}}: \mathrm{GlmM}$ and $\mathrm{CdaA}_{\mathrm{CD}}: \mathrm{GlmM}_{\mathrm{F} 369}$ complexes or complexes of $\mathrm{CdaA}_{\mathrm{CD}}$ and $\mathrm{GlmM}$ alaninesubstitution variants, cell lysates of strains overproducing the respective proteins were mixed after the French press step, then the same protein purification procedure steps as described above used for the purification of individual proteins were performed. Protein concentrations were determined using the BCA assay kit (Pierce BCA Protein Assay Kit). For each sample, the readings were taken in triplicates and then averaged to obtain the protein concentration. Purified proteins were also separated on 12\% SDS PAGE gels and detected by Coomassie staining.

\section{Microscale thermophoresis}

An MST experiment was performed to determine the binding affinity between the B. subtilis $\mathrm{CdaA}_{\mathrm{CD}}$ and $\mathrm{GlmM}$ proteins. The $\mathrm{CdaA}_{\mathrm{CD}}$ and $\mathrm{GlmM}$ were expressed and purified from $1 \mathrm{l}$ cultures as described above, however, using $20 \mathrm{mM}$ HEPES, pH 7.5, $500 \mathrm{mM} \mathrm{NaCl}$ buffer for the Ni-NTA purification and $10 \mathrm{mM}$ HEPES, $\mathrm{pH} 7.5,150 \mathrm{mM} \mathrm{NaCl}$ for the SEC purification step. Next, $\mathrm{CdaA}_{\mathrm{CD}}$ was fluorescently labeled with an amine-reactive dye using the Monolith Protein Labeling RED-NHS 2nd Generation kit (NanoTemper Technologies $\mathrm{GmbH})$. To this end, $90 \mu \mathrm{l}$ of a $40 \mu \mathrm{M} \mathrm{CdaA}_{\mathrm{CD}}$ solution was mixed with $10 \mu \mathrm{l}$ of a $400 \mu \mathrm{M}$ dye solution in $10 \mathrm{mM}$ HEPES, $\mathrm{pH} 7.5,150 \mathrm{mM} \mathrm{NaCl}, 0.05 \%$ Tween-20 buffer and incubated for $30 \mathrm{~min}$ at room temperature in the dark. Unincorporated dye was subsequently removed from the labeled protein as described in the manufacturer's instructions. Following the labeling reaction, the protein concentration was determined by nanodrop and using the Beer-Lambert equation and an extinction coefficient of 0.774 for $\mathrm{CdaA}_{\mathrm{CD}}$. For the MST experiment, a $50 \mathrm{nM}$ solution of the fluorescently labeled $\mathrm{CdaA}_{\mathrm{CD}}$ protein was mixed at a 1:1 ratio with a solution of purified GlmM protein at a starting concentration of $1600 \mu \mathrm{M}$ and ten twofold dilutions there of prepared in the purification buffer (10 mM HEPES, pH 7.5, $150 \mathrm{mM} \mathrm{NaCl}, 0.05 \%$ Tween20). The samples were filled into individual premium capillaries and subsequently loaded in the capillary tray. Each MST run was performed on a Monolith NT.115 instrument at a light emitting diode (LED) power of $95 \%$ and microscale thermophoresis (MST) power of $80 \%$ with a duration of $30 \mathrm{~s}$ laser on time (NanoTemper Technologies $\mathrm{GmbH}$ ) (43). The experiment was performed five times and average normalized fluorescence values and standard deviations determined and plotted. For the data analysis and $K_{d}$ determination, the NT Analysis Software (NanoTemper Technologies $\mathrm{GmbH}$ ) was used (43).

\section{Protein crystallization, data processing, and analysis}

For crystallization, the histidine tag was removed from the purified B. subtilis $\mathrm{CdaA}_{\mathrm{CD}}$ protein. This was done by incubating $10 \mathrm{mg}$ purified protein with $20 \mathrm{U}$ thrombin overnight at $4{ }^{\circ} \mathrm{C}$ with agitation. The following day, the tag less $\mathrm{CdaA}_{\mathrm{CD}}$ was purified by size-exclusion chromatography as described above. The $\mathrm{CdaA}_{\mathrm{CD}}$ protein was crystallized at a concentration of $4 \mathrm{mg} / \mathrm{ml}$ in $0.1 \mathrm{M}$ sodium cacodylate $\mathrm{pH} 6.5,0.1 \mathrm{M}$ ammonium sulfate, $0.3 \mathrm{M}$ sodium formate, 6\% PEG 8000, 3\% $\gamma$-PGA via the vapor diffusion method. The crystal screens for B. subtilis GlmM (including the His tag) were set up at a concentration of $10 \mathrm{mg} / \mathrm{ml}$ and protein crystals were obtained in two different conditions. The structure with bound $\mathrm{PO}_{4}$ (GlmM: $\mathrm{PO}_{4}$ ) was obtained in the Morpheus screen containing $0.1 \mathrm{M}$ buffer system 1 (Imidazole; MES, pH 6.5), $0.09 \mathrm{M} \mathrm{NPS}$ $\left(\mathrm{NaNO}_{3} ; \mathrm{Na}_{2} \mathrm{HPO}_{4} ;\left(\mathrm{NH}_{4}\right)_{2} \mathrm{SO}_{4}\right)$, and $37.5 \%$ MPD_P1K_P3350 (75\% MPD, PEG 1K, PEG 3350) and the divalent-ion bound crystal structure (GlmM:metal ion) was obtained in $0.05 \mathrm{M}$ Magnesium chloride hexahydrate, 0.1 M HEPES pH 7.5, 30\% $\mathrm{v} / \mathrm{v}$ Polyethylene glycol monomethyl ether 550 buffer. The crystals for the $\mathrm{CdaA}_{\mathrm{CD}}$ : GlmM $\mathrm{F}_{\mathrm{F} 69}$ complex were set up at a protein concentration of $10 \mathrm{mg} / \mathrm{ml}$ and crystals were obtained in $0.12 \mathrm{M}$ alcohols, $0.1 \mathrm{M}$ buffer system (Imidazole; MES, pH 6.5) and 30\% GOL_P4K (60\% glycerol, PEG 4K) (Complex 1) and $0.1 \mathrm{M}$ carboxylic acids, $0.1 \mathrm{M}$ buffer system 1 (Imidazole; MES, pH 6.5) and 30\% GOL_P4K (60\% glycerol, PEG 4K) (Complex 2). The crystals were fished and stored in liquid nitrogen to test for diffraction at the I03 beamline at the Diamond Light Source (Harwell Campus). Data were reduced with DIALS (44) and scaled and merged with AIMLESS (45). The structures of $\mathrm{CdaA}_{\mathrm{CD}}$ and $\mathrm{GlmM}$ were solved by the molecular replacement method using the program MRPHASER (46) in the Phenix suite (47), using the L. monocytogenes CdaA structure (PDB 4RV7; (21)) and 
B. anthracis GlmM structure (PDB 3PDK; (37)) as the search models, respectively. To solve the phase problem for the structure of the $\mathrm{CdaA}_{\mathrm{CD}}: \mathrm{GlmM}_{\mathrm{F} 369}$ complex, dimers of B. subtilis $\mathrm{CdaA}_{\mathrm{CD}}$ and $\mathrm{GlmM}$ (each) were used as the search models using the MR-PHASER program in Phenix. The models were manually built using COOT (48) followed by iterative cycles of structure refinement using the Phenix-Refine program (49). The final refined structures were analyzed using the PDBePISA server (36) to identify buried interface areas for each protein. To search for conserved residues among the phylogenetically related homologs, a protein BLAST search was performed using $B$. subtilis $\mathrm{CdaA}_{\mathrm{CD}}$ and $\mathrm{GlmM}$ amino acid sequences as query sequences and a multiple sequence alignment (MSA) of the top 2500 homologs found in Firmicutes was prepared. The MSA was then used to identify conserved residues among the homologs using the ConSurf server (50).

\section{$C d a A_{C D}$ activity and inhibition assays}

To assess the activity of the $B$. subtilis $\mathrm{CdaA}_{\mathrm{CD}}$ enzymes, $20 \mu \mathrm{l}$ enzyme reactions were set up in $100 \mathrm{mM} \mathrm{NaCl}, 40 \mathrm{mM}$ HEPES pH 7 buffer containing $10 \mathrm{mM} \mathrm{MnCl}_{2}$ (or $10 \mathrm{mM}$ $\mathrm{MgCl}_{2}$ or $10 \mathrm{mM} \mathrm{CoCl}_{2}$ for metal dependent assays), $100 \mathrm{mM}$ ATP spiked with a- $\mathrm{P}^{32}$-labeled ATP (PerkinElmer; using $0.4 \mu \mathrm{l}$ of a $3.3 \mu \mathrm{M}, 250 \mu \mathrm{Ci}$ solution per $20 \mu \mathrm{l}$ reaction), and $5 \mu \mathrm{M}$ $\mathrm{CdaA}_{\mathrm{CD}}$ enzyme. The mixture was incubated at $37^{\circ} \mathrm{C}$ for $4 \mathrm{~h}$, followed by heat inactivation at $95{ }^{\circ} \mathrm{C}$ for $5 \mathrm{~min}$. After centrifugation for $10 \mathrm{~min}$ at $21,000 \mathrm{~g}, 1 \mu \mathrm{l}$ of the mixture was deposited onto a polyethylenimine-modified cellulose TLC plate (Millipore), and nucleotides separated by running the plate for 20 min using a $3.52 \mathrm{M}\left(\mathrm{NH}_{4}\right)_{2} \mathrm{SO}_{4}$ and $1.5 \mathrm{M} \mathrm{KH}_{2} \mathrm{PO}_{4}$ buffer system mixed at a 1:1.5 v/v ratio. Radioactive signals for ATP and the c-di-AMP reaction product were detected using a Typhoon FLA-700 phosphor imager. The bands were quantified using the ImageQuant program and the obtained values used to calculate the percent conversion of ATP to c-di-AMP. For the time course experiment, a $100 \mu$ reaction mixture was prepared as described above and incubated at $37{ }^{\circ} \mathrm{C}$. Ten microliter aliquots were removed at the indicated time points and the enzyme reactions stopped by incubation the removed aliquots at $95^{\circ} \mathrm{C}$ for $5 \mathrm{~min}$. To assess the activity of $\mathrm{CdaA} \mathrm{AD}_{\mathrm{CD}}$ in the presence of $\mathrm{GlmM}$ or $\mathrm{GlmM}_{\mathrm{F} 369}$, the full-length $\mathrm{GlmM}$ protein or C-terminally truncated GlmM variant was added to the reaction mixture at a $1: 2\left(\mathrm{CdaA}_{\mathrm{CD}}: \mathrm{GlmM}\right.$ or $\mathrm{CdaA}_{\mathrm{CD}}$ : $\mathrm{GlmM}_{\mathrm{F} 369}$ ) molar ratio and the reactions incubated at $37{ }^{\circ} \mathrm{C}$ for $4 \mathrm{~h}$, stopped, and analyzed as described above. The enzyme activity assays were performed in triplicates with two independently purified protein preparations.

\section{SAXS sample preparation and analysis}

For the SAXS analysis, purified $\mathrm{CdaA}_{\mathrm{CD}}, \mathrm{GlmM}$, $\mathrm{CdaA}_{\mathrm{CD}}$ :GlmM complex, and $\mathrm{CdaA}_{\mathrm{CD}}: \mathrm{GlmM}_{\mathrm{F} 369}$ complex protein samples were purified by size-exclusion chromatography as described above and subsequently concentrated to $5 \mathrm{mg} / \mathrm{ml}$ for $\mathrm{CdaA}_{\mathrm{CD}}, 24 \mathrm{mg} / \mathrm{ml}$ each for $\mathrm{GlmM}$ and the $\mathrm{CdaA}_{\mathrm{CD}}: \mathrm{GlmM}$ complex and $10 \mathrm{mg} / \mathrm{ml}$ for the
$\mathrm{CdaA}_{\mathrm{CD}}: \mathrm{GlmM}_{\mathrm{F} 369}$ complex. Next, $50 \mu$ l protein samples were loaded on a high pressure Shodex column (KW403: range $10 \mathrm{kDa}-700 \mathrm{kDa}$ ) fitted to an Agilent 1200 HPLC system at the B21 beamline at the Diamond Light Source. The size-exclusion column was equilibrated with $30 \mathrm{mM}$ Tris $\mathrm{pH} 7.5,150 \mathrm{mM}$ $\mathrm{NaCl}$ buffer prior to loading the protein sample and the data were collected continuously throughout the protein elution. The analysis of the datasets was done via ScÅtter (51) using the scattering frames corresponding to the elution peaks. The $a b$ initio analysis of the SAXS data to reconstruct a low-resolution shape of the model was done using the DAMAVER (DAMMIF) program (52), which performs 13 ab initio runs to generate models from each run that were averaged to determine the most persistent three-dimensional shape of the protein. The cross-correlation Normalized Spatial Discrepancy (NSD) values were calculated using DAMAVER (DAMSEL) (52) from each of the 13 generated models. The mean NSD values calculated for each of the protein were: $0.591 \pm 0.088$ $\left(\mathrm{CdaA}_{\mathrm{CD}}\right), \quad 0.598 \pm 0.014 \quad(\mathrm{GlmM}), \quad 1.201 \pm 0.099$ $\left(\mathrm{CdaA}_{\mathrm{CD}}: \mathrm{GlmM}_{\mathrm{F} 369}\right.$ complex), and $0.661 \pm 0.064$ $\left(\mathrm{CdaA}_{\mathrm{CD}}\right.$ :GlmM complex). The program Chimera (53) was used to visualize the reconstructed SAXS maps. The crystal structures of $\mathrm{CdaA}_{\mathrm{CD}}$ and $\mathrm{GlmM}$ dimers as well as $\mathrm{CdaA}_{\mathrm{CD}}$ :GlmM $\mathrm{G}_{\mathrm{F} 369}$ complex were fitted in the respective SAXS envelopes in Chimera using the one-step fit function. For the $\mathrm{CdaA}_{\mathrm{CD}}$ : $\mathrm{GlmM}$ complex data, a structural model of the $\mathrm{CdaA}_{\mathrm{CD}}$ full-length GlmM complex was generated based on the crystal structure of the $\mathrm{CdaA}_{\mathrm{CD}}$ : $\mathrm{GlmM}_{\mathrm{F} 369}$ complex, which was then fitted into the SAXS envelope data using Chimera.

\section{Data availability}

The structure coordinates of the B. subtilis proteins were deposited in the Protein Database (https://www.rcsb.org), under PDB codes 6HUW (CdaA $\mathrm{CD}), 7 \mathrm{OJR}$ (GlmM: $\mathrm{PO}_{4}$ bound), 7OML (GlmM: metal bound) and 7OLH $\left(\mathrm{CdaA}_{\mathrm{CD}}: \mathrm{GlmM}_{\mathrm{F} 369}\right.$ Complex 1), and 7OJS $\left(\mathrm{CdaA}_{\mathrm{CD}}: \mathrm{GlmM}_{\mathrm{F} 369}\right.$ Complex 2). SAXS models were deposited in the SASBDB database, under the accession codes SASDL25 (Complex CdaA $\mathrm{CD}_{\mathrm{CD}}$ GlmM), SASDMQ5 (Complex $\left.\mathrm{CdaA}_{\mathrm{CD}}: \mathrm{GlmM}_{\mathrm{F} 369}\right)$, SASDLZ4 (GlmM), and SASDLY4 $\left(\mathrm{CdaA}_{\mathrm{CD}}\right)$.

Supporting information-This article contains a supporting information $(36,50,51,54,55)$.

Acknowledgments-We would like to thank Christiaan van Ooij for helpful comments on the manuscript. The crystallization facility at Imperial College was funded by the BBSRC (BB/D524840/1) and the Wellcome Trust (202926/Z/16/Z). X-Ray datasets for $\mathrm{CdaA}_{\mathrm{CD}}$, $\mathrm{GlmM}$, and the $\mathrm{CdaA}_{\mathrm{CD}}$ :GlmM complex 2 were collected at the I03 beamline and the $\mathrm{CdaA}_{\mathrm{CD}}$ :GlmM complex 1 dataset was collected at the I04 beamline at the Diamond Light Source (Didcot, UK). The SAXS data were collected at the B21 beamline at the Diamond Light Source (Didcot, UK).

Author contributions-M. P., T. T., P. S. F., and A. G. conceptualization; M. P., T. T., C. M., F. H., R. M. L. M., and A. G. formal 


\section{B. subtilis CdaA:GImM complex}

analysis; M. P., T. T., C. M., and F. H. investigation; R. M. L. M., P. S. F., and A. G. supervision; M. P. validation; M. P., P. S. F., and A. G. writing-original draft; T. T., C. M., F. H., and R. M. L. M. writingreview and editing.

Funding and additional information-This work was funded by the MRC grant MR/P011071/1 to A. G. and P. S. F. and the Wellcome Trust grant $210671 / \mathrm{Z} / 18 / \mathrm{Z}$ to A. G.

Conflict of interest-The authors declare no conflicts of interest in regard to this manuscript.

Abbreviations-The abbreviations used are: c-di-AMP, cyclic-diadenosine monophosphate; $\mathrm{CdaA}_{\mathrm{CD}}, \mathrm{CdaA}$ catalytic domain; DAC, diadenylate cyclase; DacA $A_{C D}$, DacA catalytic domain; MST, microscale thermophoresis; NSD, normalized spatial discrepancy; SAXS, small-angle X-ray scattering data.

\section{References}

1. Hengge, R., Gründling, A., Jenal, U., Ryan, R., and Yildiz, F. (2016) Bacterial signal transduction by cyclic di-GMP and other nucleotide second messengers. J. Bacteriol. 198, 15-26

2. Krasteva, P. V., and Sondermann, H. (2017) Versatile modes of cellular regulation via cyclic dinucleotides. Nat. Chem. Biol. 13, 350-359

3. Witte, G., Hartung, S., Buttner, K., and Hopfner, K. P. (2008) Structural biochemistry of a bacterial checkpoint protein reveals diadenylate cyclase activity regulated by DNA recombination intermediates. Mol. Cell 30, $167-178$

4. Bai, Y., Yang, J., Zarrella, T. M., Zhang, Y., Metzger, D. W., and Bai, G. (2014) Cyclic di-AMP impairs potassium uptake mediated by a cyclic diAMP binding protein in Streptococcus pneumoniae. J. Bacteriol. 196, 614623

5. Whiteley, A. T., Garelis, N. E., Peterson, B. N., Choi, P. H., Tong, L., Woodward, J. J., and Portnoy, D. A. (2017) c-di-AMP modulates Listeria monocytogenes central metabolism to regulate growth, antibiotic resistance and osmoregulation. Mol. Microbiol. 104, 212233

6. Huynh, T. N., Choi, P. H., Sureka, K., Ledvina, H. E., Campillo, J., Tong, L., and Woodward, J. J. (2016) Cyclic di-AMP targets the cystathionine beta-synthase domain of the osmolyte transporter OpuC. Mol. Microbiol. 102, 233-243

7. Corrigan, R. M., Campeotto, I., Jeganathan, T., Roelofs, K. G., Lee, V. T., and Gründling, A. (2013) Systematic identification of conserved bacterial c-di-AMP receptor proteins. Proc. Natl. Acad. Sci. U. S. A. 110, 90849089

8. Gundlach, J., Herzberg, C., Kaever, V., Gunka, K., Hoffmann, T., Weiss, M., Gibhardt, J., Thurmer, A., Hertel, D., Daniel, R., Bremer, E., Commichau, F. M., and Stülke, J. (2017) Control of potassium homeostasis is an essential function of the second messenger cyclic di-AMP in Bacillus subtilis. Sci. Signal. 10, eaal3011

9. Corrigan, R. M., Abbott, J. C., Burhenne, H., Kaever, V., and Gründling, A. (2011) c-di-AMP is a new second messenger in Staphylococcus aureus with a role in controlling cell size and envelope stress. PLoS Pathog. 7, e1002217

10. Luo, Y., and Helmann, J. D. (2012) Analysis of the role of Bacillus subtilis sigma(M) in beta-lactam resistance reveals an essential role for c-di-AMP in peptidoglycan homeostasis. Mol. Microbiol. 83, 623-639

11. Corrigan, R. M., Bowman, L., Willis, A. R., Kaever, V., and Gründling, A. (2015) Cross-talk between two nucleotide-signaling pathways in Staphylococcus aureus. J. Biol. Chem. 290, 5826-5839

12. Dengler, V., McCallum, N., Kiefer, P., Christen, P., Patrignani, A., Vorholt, J. A., Berger-Bächi, B., and Senn, M. M. (2013) Mutation in the c-di-AMP cyclase dacA affects fitness and resistance of methicillin resistant Staphylococcus aureus. PLoS One 8, e73512
13. Woodward, J. J., Iavarone, A. T., and Portnoy, D. A. (2010) c-di-AMP secreted by intracellular Listeria monocytogenes activates a host type I interferon response. Science 328, 1703-1705

14. Witte, C. E., Whiteley, A. T., Burke, T. P., Sauer, J. D., Portnoy, D. A., and Woodward, J. J. (2013) Cyclic di-AMP is critical for Listeria monocytogenes growth, cell wall homeostasis, and establishment of infection. mBio 4, e00282-13

15. Oppenheimer-Shaanan, Y., Wexselblatt, E., Katzhendler, J., Yavin, E., and Ben-Yehuda, S. (2011) c-di-AMP reports DNA integrity during sporulation in Bacillus subtilis. EMBO Rep. 12, 594-601

16. Devaux, L., Sleiman, D., Mazzuoli, M. V., Gominet, M., Lanotte, P., TrieuCuot, P., Kaminski, P. A., and Firon, A. (2018) Cyclic di-AMP regulation of osmotic homeostasis is essential in group B Streptococcus. PLoS Genet. 14, e1007342

17. Mehne, F. M., Gunka, K., Eilers, H., Herzberg, C., Kaever, V., and Stülke, J. (2013) Cyclic di-AMP homeostasis in Bacillus subtilis: Both lack and high level accumulation of the nucleotide are detrimental for cell growth. J. Biol. Chem. 288, 2004-2017

18. Commichau, F. M., Heidemann, J. L., Ficner, R., and Stülke, J. (2019) Making and breaking of an essential poison: The cyclases and phosphodiesterases that produce and degrade the essential second messenger cyclic di-AMP in bacteria. J. Bacteriol. 201, e00462-18

19. Rao, F., See, R. Y., Zhang, D., Toh, D. C., Ji, Q., and Liang, Z. X. (2010) YybT is a signaling protein that contains a cyclic dinucleotide phosphodiesterase domain and a GGDEF domain with ATPase activity. J. Biol. Chem. 285, 473-482

20. Huynh, T. N., Luo, S., Pensinger, D., Sauer, J. D., Tong, L., and Woodward, J. J. (2015) An HD-domain phosphodiesterase mediates cooperative hydrolysis of c-di-AMP to affect bacterial growth and virulence. Proc. Natl. Acad. Sci. U. S. A. 112, E747-E756

21. Rosenberg, J., Dickmanns, A., Neumann, P., Gunka, K., Arens, J., Kaever, V., Stülke, J., Ficner, R., and Commichau, F. M. (2015) Structural and biochemical analysis of the essential diadenylate cyclase CdaA from Listeria monocytogenes. J. Biol. Chem. 290, 6596-6606

22. Zheng, C., Ma, Y., Wang, X., Xie, Y., Ali, M. K., and He, J. (2015) Functional analysis of the sporulation-specific diadenylate cyclase CdaS in Bacillus thuringiensis. Front. Microbiol. 6, 908

23. Müller, M., Deimling, T., Hopfner, K. P., and Witte, G. (2015) Structural analysis of the diadenylate cyclase reaction of DNA-integrity scanning protein A (DisA) and its inhibition by 3'-dATP. Biochem. J. 469, 367-374.

24. Mehne, F. M., Schroder-Tittmann, K., Eijlander, R. T., Herzberg, C., Hewitt, L., Kaever, V., Lewis, R. J., Kuipers, O. P., Tittmann, K., and Stülke, J. (2014) Control of the diadenylate cyclase CdaS in Bacillus subtilis: An autoinhibitory domain limits cyclic di-AMP production. J. Biol. Chem. 289, 21098-21107

25. Fahmi, T., Port, G. C., and Cho, K. H. (2017) c-di-AMP: An essential molecule in the signaling pathways that regulate the viability and virulence of Gram-positive bacteria. Genes (Basel) 8, 197

26. Corrigan, R. M., and Gründling, A. (2013) Cyclic di-AMP: Another second messenger enters the fray. Nat. Rev. Microbiol. 11, 513-524.

27. Torres, R., Carrasco, B., Gandara, C., Baidya, A. K., Ben-Yehuda, S., and Alonso, J. C. (2019) Bacillus subtilis DisA regulates RecA-mediated DNA strand exchange. Nucleic Acids Res. 47, 5141-5154.

28. Tosi, T., Hoshiga, F., Millership, C., Singh, R., Eldrid, C., Patin, D., Mengin-Lecreulx, D., Thalassinos, K., Freemont, P., and Gründling, A. (2019) Inhibition of the Staphylococcus aureus c-di-AMP cyclase DacA by direct interaction with the phosphoglucosamine mutase GlmM. PLoS Pathog. 15, e1007537

29. Gundlach, J., Mehne, F. M., Herzberg, C., Kampf, J., Valerius, O., Kaever, V., and Stülke, J. (2015) An essential poison: Synthesis and degradation of cyclic di-AMP in Bacillus subtilis. J. Bacteriol. 197, 3265-3274.

30. Heidemann, J. L., Neumann, P., Dickmanns, A., and Ficner, R. (2019) Crystal structures of the c-di-AMP-synthesizing enzyme CdaA. J. Biol. Chem. 294, 10463-10470

31. Zhu, Y., Pham, T. H., Nhiep, T. H., Vu, N. M., Marcellin, E., Chakrabortti, A., Wang, Y., Waanders, J., Lo, R., Huston, W. M., Bansal, N., Nielsen, L. K., Liang, Z. X., and Turner, M. S. (2016) Cyclic-di-AMP synthesis by the diadenylate cyclase CdaA is modulated by the 


\section{B. subtilis CdaA:GImM complex}

peptidoglycan biosynthesis enzyme GlmM in Lactococcus lactis. Mol. Microbiol. 99, 1015-1027

32. Pham, T. H., Liang, Z. X., Marcellin, E., and Turner, M. S. (2016) Replenishing the cyclic-di-AMP pool: Regulation of diadenylate cyclase activity in bacteria. Curr. Genet. 62, 731-738

33. Gibhardt, J., Heidemann, J. L., Bremenkamp, R., Rosenberg, J., Seifert, R., Kaever, V., Ficner, R., and Commichau, F. M. (2020) An extracytoplasmic protein and a moonlighting enzyme modulate synthesis of c-di-AMP in Listeria monocytogenes. Environ. Microbiol. 22, 2771-2791

34. Rismondo, J., Gibhardt, J., Rosenberg, J., Kaever, V., Halbedel, S., and Commichau, F. M. (2016) Phenotypes associated with the essential diadenylate cyclase CdaA and its potential regulator CdaR in the human pathogen Listeria monocytogenes. J. Bacteriol. 198, 416-426

35. Barreteau, H., Kovac, A., Boniface, A., Sova, M., Gobec, S., and Blanot, D. (2008) Cytoplasmic steps of peptidoglycan biosynthesis. FEMS Microbiol. Rev. 32, 168-207

36. Krissinel, E., and Henrick, K. (2007) Inference of macromolecular assemblies from crystalline state. J. Mol. Biol. 372, 774-797

37. Mehra-Chaudhary, R., Mick, J., and Beamer, L. J. (2011) Crystal structure of Bacillus anthracis phosphoglucosamine mutase, an enzyme in the peptidoglycan biosynthetic pathway. J. Bacteriol. 193, 4081-4087

38. Zheng, H., Cooper, D. R., Porebski, P. J., Shabalin, I. G., Handing, K. B., and Minor, W. (2017) CheckMyMetal: A macromolecular metal-binding validation tool. Acta Crystallogr. D Struct. Biol. 73, 223-233

39. Celniker, G., Nimrod, G., Ashkenazy, H., Glaser, F., Martz, E., Mayrose, I., Pupko, T., and Ben-Tal, N. (2013) ConSurf: Using evolutionary data to raise testable hypotheses about protein function. Isr. J. Chem. 53, 199-206

40. Tan, E., Rao, F., Pasunooti, S., Pham, T. H., Soehano, I., Turner, M. S., Liew, C. W., Lescar, J., Pervushin, K., and Liang, Z. X. (2013) Solution structure of the PAS domain of a thermophilic YybT protein homolog reveals a potential ligand-binding site. J. Biol. Chem. 288, 11949-11959

41. Rao, F., Ji, Q., Soehano, I., and Liang, Z. X. (2011) Unusual heme-binding PAS domain from YybT family proteins. J. Bacteriol. 193, 1543-1551

42. Raguse, M., Torres, R., Seco, E. M., Gandara, C., Ayora, S., Moeller, R., and Alonso, J. C. (2017) Bacillus subtilis DisA helps to circumvent replicative stress during spore revival. DNA Repair (Amst.) 59, 57-68

43. Jerabek-Willemsen, M., André, T., Wanner, R., Roth, H. M., Duhr, S., Baaske, P., and Breitsprecher, D. (2014) MicroScale thermophoresis: Interaction analysis and beyond. J. Mol. Struct. 1077, 101-113

44. Winter, G., Waterman, D. G., Parkhurst, J. M., Brewster, A. S., Gildea, R. J., Gerstel, M., Fuentes-Montero, L., Vollmar, M., Michels-Clark, T.,
Young, I. D., Sauter, N. K., and Evans, G. (2018) DIALS: Implementation and evaluation of a new integration package. Acta Crystallogr. D Struct. Biol. 74, 85-97

45. Evans, P. R., and Murshudov, G. N. (2013) How good are my data and what is the resolution? Acta Crystallogr. D Biol. Crystallogr. 69, 12041214

46. Bunkoczi, G., Echols, N., McCoy, A. J., Oeffner, R. D., Adams, P. D., and Read, R. J. (2013) Phaser.MRage: Automated molecular replacement. Acta Crystallogr. D Biol. Crystallogr. 69, 2276-2286

47. Liebschner, D., Afonine, P. V., Baker, M. L., Bunkoczi, G., Chen, V. B., Croll, T. I., Hintze, B., Hung, L. W., Jain, S., McCoy, A. J., Moriarty, N. W., Oeffner, R. D., Poon, B. K., Prisant, M. G., Read, R. J., et al. (2019) Macromolecular structure determination using X-rays, neutrons and electrons: Recent developments in phenix. Acta Crystallogr. D Struct. Biol. $75,861-877$

48. Emsley, P., Lohkamp, B., Scott, W. G., and Cowtan, K. (2010) Features and development of Coot. Acta Crystallogr. D Biol. Crystallogr. 66, 486501

49. Headd, J. J., Echols, N., Afonine, P. V., Grosse-Kunstleve, R. W., Chen, V. B., Moriarty, N. W., Richardson, D. C., Richardson, J. S., and Adams, P. D. (2012) Use of knowledge-based restraints in phenix.refine to improve macromolecular refinement at low resolution. Acta Crystallogr. D Biol. Crystallogr. 68, 381-390

50. Ashkenazy, H., Abadi, S., Martz, E., Chay, O., Mayrose, I., Pupko, T., and Ben-Tal, N. (2016) ConSurf 2016: An improved methodology to estimate and visualize evolutionary conservation in macromolecules. Nucleic Acids Res. 44, W344-W350

51. Förster, S., Apostol, L., and Bras, W. (2010) Scatter: Software for the analysis of nano- and mesoscale small-angle scattering. J. Appl. Crystallogr. 43, 639-64.6

52. Franke, D., and Svergun, D. I. (2009) DAMMIF, a program for rapid abinitio shape determination in small-angle scattering. J. Appl. Crystallogr. $42,342-346$

53. Pettersen, E. F., Goddard, T. D., Huang, C. C., Couch, G. S., Greenblatt, D. M., Meng, E. C., and Ferrin, T. E. (2004) UCSF Chimera-a visualization system for exploratory research and analysis. J. Comput. Chem. 25, $1605-1612$

54. Burkholder, P. R., and Giles, N. H., Jr. (1947) Induced biochemical mutations in Bacillus subtilis. Am. J. Bot. 34, 345-348

55. Laskowski, R. A., and Swindells, M. B. (2011) LigPlot+: Multiple ligandprotein interaction diagrams for drug discovery. J. Chem. Inf. Model. 51, 2778-2786 